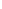


La Revista de Arquitectura (ISSN 16570308 impresa y ISSN 2357626X en línea) es una publicación seriada, arbitrada mediante revisión por pares, indexada y de acceso abierto, donde se publican principalmente resultados de investigación originales e inéditos.

Está dirigida a la comunidad académica y profesional de las áreas afines a la disciplina (Arquitectura y Urbanismo). El primer número se publicó en 1999. Es editada por la Facultad de Diseño y el Centro de Investigaciones -CIFAR- de la UNIVERSIDAD CATÓLICA DE COLOMBIA en Bogotá, Colombia.

La revista se estructura en tres secciones correspondientes a las líneas de investigación activas y aprobadas por la institución y una cuarta correspondiente a la dinámica propia de la Facultad de Diseño.

CULTURA Y ESPACIO URBANO. En esta sección se publican los artículos que se refieren a fenómenos sociales en relación con el espacio urbano, atendiendo aspectos de la historia, el patrimonio cultural y físico, y la estructura formal de las ciudades y el territorio.

PROYECTO ARQUITECTÓNICO Y URBANO. En esta sección se presentan artículos sobre el concepto de proyecto, entendido como elemento que define y orienta las condiciones proyectuales que devienen en los hechos arquitectónicos o urbanos, y la forma como estos se convierten en un proceso de investigación y nuevo de conocimiento. También se presentan proyectos que sean resultados de investigación, que se validan a través de la ejecución y transformación en obra construida del proceso investigativo. También se contempla la publicación de investigaciones relacionadas con la pedagogía y didáctica de la arquitectura, el urbanismo y el diseño.

TECNOLOGÍA, MEDIOAMBIENTE Y SOSTENIBILIDAD. En esta sección se presentan artículos acerca de sistemas estructurales, materiales y procesos constructivos, medioambiente y gestión, relacionados con el entorno social-cultural, ecológico y económico.
DeSDE LA FACUlTAD. En esta sección se publican artículos generados en la Facultad de Diseño relacionados con las actividades de docencia, extensión o internacionalización, las cuales son reflejo de la dinámica y de las actividades realizadas por docentes, estudiantes y egresados; esta sección no puede superar el $20 \%$ del contenido con soporte investigativo.

Los objetivos de la Revista de Arquitectura son:

- Promover la investigación, el desarrollo y la difusión del conocimiento generado a nivel local, nacional e internacional.

- Conformar un espacio para la construcción de comunidades académicas y la discusión en torno a las secciones definidas.

- Fomentar la diversidad institucional y geográfica de los autores que participan en la publicación.

- Potenciar la discusión de experiencias e intercambios científicos entre investigadores y profesionales.

- Contribuir a la visión integral de la arquitectura, por medio de la concurrencia y articulación de las secciones mediante la publicación de artículos de calidad.

- Publicar artículos originales e inéditos que han pasado por revisión de pares, para asegurar que se cumplen con las normas de calidad, validez científica y ética editorial e investigativa.

- Fomentar la divulgación de las investigaciones y actividades que se desarrollan en la Facultad de Diseño de la UNIVERSIDAD CATÓLICA DE COLOMBIA.

Palabras clave de la Revista de Arquitectura: Arquitectura, diseño, educación arquitectónica, proyecto y construcción urbanismo.

Key words for Revista de Arquitectura: Architecture, design, architectural education, urban planning, design-build.

Idiomas de publicación: Español, Inglés, Portugués, Francés.

Título corto: RevArq
A El editor y los autores son responsables de los artículos aquí publicados.

Los autores son los responsables del material gráfico publicado.

Esta revista se acoge una licencia Creative Commons (CC) de Atribución - No comercial Compartir igual, 4.0 Internacional: "El material creado puede ser distribuido, copiado y exhibido por terceros si se muestra en los créditos. No se puede obtener ningún beneficio comercial y las obras derivadas tienen que estar bajo los mismos términos de licencia que el trabajo original".

Para más información:

http://co.creativecommons.org/tipos-de-licencias/

Universidad Católica de Colombia (2015).

Revista de Arquitectura, 17 (1), 1-112.

ISSN: 1657-0308 E-ISSN 2357-626X

(A) Especificaciones:

Formato: $34 \times 24 \mathrm{~cm}$

Papel: Mate $115 \mathrm{~g}$

Tintas: Negro y policromía

Periodicidad: Anual

\section{(A) CANie}

Oвjetivo:

La Revista de Arquitectura está interesada en establecer canje con publicaciones académicas, profesionales o científicas, del área del Diseño, la Arquitectura y el Urbanismo o la educación superior, como medio de reconocimiento y discusión de la producción científica en el campo de acción de la publicación.

MeCANISMO:

Para establecer Canje por favor descargar, diligenciar y enviar al correo electrónico de la Revista el formato:

RevArq FP20 Canjes

\section{A Contacto}

DIRECCIÓN POSTAL:

Avenida Caracas N ${ }^{\circ} 46$ - 72. Universidad Católica de Colombia. Bogotá D.C.- Colombia

Código postal: 111311

Centro de Investigaciones (CIFAR).

Sede El Claustro. Bloque "L", 4 piso, Diag. 46를. No. 15b-10.

Arq. César Andrés Eligio Triana

Teléfonos: + 57 (1) 3277300 - 3277333

Ext. 3109; 3112 ó 5146

Fax:+57 (1) 2858895

CoRREO ElECTRÓNICO:

revistadearquitectura@ucatolica.edu.co

cifar@ucatolica.edu.co

PÁGINA WEB:

http://editorial.ucatolica.edu.co/ojsucatolica/revistas ucatolica/ index.php/RevArq/

EDITOR:

Mg. en Arq. César Andrés Eligio Triana celigio@ucatolica.edu.co

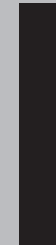


UNIVERSIDAD CATÓLICA DE COLOMBIA

PRESIDENTE

Édgar Gómez Betancourt

VICEPRESIDENTE - RECTOR

Francisco José Gómez Ortiz

VICERRECTOR JURÍDICO Y DEL MEDIO

UNIVERSITARIO

Edwin de Jesús Horta Vásquez

VICERRECTOR ADMINISTRATIVO

Édgar Gómez Ortiz

DECANO ACADÉMICO

Elvers Medellín Lozano

DIRECTORA DE INVESTIGACIONES

Elisa Urbina Sánchez

DIRECTORA EDITORIAL

Stella Valbuena García

\section{FACULTAD DE DISEÑO}

DECANO

Werner Gómez Benítez

DIRECTOR DE DOCENCIA

Jorge Gutiérrez Martínez

DIRECTOR DE EXTENSIÓN

Adriana Pedraza Pacheco

DIRECTOR DE INVESTIGACIÓN

Hernando Verdugo Reyes

DIRECTOR DE GESTIÓN DE CALIDAD

Augusto Forero La Rotta

COMITÉ ASESOR EXTERNO

FACUlTAD DE DisEÑo

Alberto Miani Uribe

Giovanni Ferroni Del Valle

Samuel Ricardo Vélez

Lorenzo Castro

\section{FACULTAD DE DISEÑO}

\section{Centro de INVESTIGACIONES - CIFAR}

\section{A. Daltectura}

\section{REVISTA DE ACCESO ABIERTO, \\ ARBITRADA E INDEXADA}

Publindex Categoría B. Índice Bibliográfico Nacional IBN. Colombia.

Redalyc. Red de Revistas Científicas de América Latina y el Caribe, España y Portugal. Sistema de Información Científica. México.

Proquest. ProQuest Research LibraryProQuest Research Library ProQuest Research Library Estados Unidos

Ebsco. EBSCOhost Research Databases. Estados Unidos.

Latindex. Sistema Regional de Información en Línea para Revistas Científicas de América Latina, el Caribe España y Portugal (Directorio y catálogo). México. Clase. Base de datos bibliográfica de revistas de ciencias sociales y humanidades. Universidad Autónoma México.

Dialnet. Fundación Dialnet - Biblioteca de la Universidad de La Rioja. España. Actualidad Iberoamericana. (Índice de Revistas) Centro de Información Tecnológica (CIT). Chile. Arla. Asociación de revistas latinoamericanas de arquitectura.

EDITORIAL

Av. Garacas $N^{\circ} 46-72$, piso 5

Teléfono: 3277300 Ext. 5145

editorial@ucatolica.edu.co

www.ucatolica.edu.co

hitp://publicaciones.ucatolica.edu.co/

IMPRESIÓN:

ESCALA Taller Litográfico

Calle $30 \mathrm{~N}^{\circ} 17-52$ - (057 I) 2320482

Junio de 2015

\section{REVISTA DE ARQUITECTURA}

DIRECTOR

Werner Gómez Benítez

EDITOR

César Andrés Eligio Triana

EDITOR ASOCIADO

Andrés Ávila Gómez

EDITOR DE SECCIÓN

Carolina Rodríguez Ahumada

CONSEJO EDITORIAL

Werner Gómez Benítez

Jorge Gutiérrez Martínez

César Andrés Eligio Triana

Hernando Verdugo Reyes

\section{EQUIPO EDITORIAL}

COORDINADORA EDITORIAL

María Paula Godoy Casasbuenas mpgodoy@ucatolica.edu.co

DisEÑO Y MONTAJE

Juanita Isaza

juanaisaza@gmail.com

TRADUCTORES

INGLÉS

Massayel Cuéllar Hernández massacuellar@gmail.com

FRANCÉS

Andrés Ávila Gómez

andresavigom@gmail.com

CORRECTORA DE ESTILO

María José Díaz Granados M. mariajose_dgm@yahoo.com.co

PÁGINA WEB

Centro de investigaciones (CIFAR)

DISTRIBUCIÓN Y CANJES

Claudia Álvarez Duquino

calvarez@ucatolica.edu.co
COMITÉ EDITORIAL

\section{CULTURA Y ESPACIO URBANO}

Sonia Berjman, $\mathrm{PhD}$

ICOMOS-IFLA, Buenos Aires, Argentina

Beatriz García Moreno, PhD

Universidad Nacional de Colombia. Bogotá, Colombia

Juan Carlos Pérgolis, MSc

Universidad Piloto de Colombia. Bogotá, Colombia

René Julio Castillo, MSc PhD (Estudios) Universidad del Rosario. Bogotá, Colombia

\section{PROYECTO ARQUITECTÓNICO Y URBANO}

Jean-Philippe Garric, PhD, HDR

Université Paris I Panthéon-Sorbonne. Paris, Francia

Hugo Mondragón López, PhD Pontificia Universidad Católica de Chile. Santiago, Chile

Juan Pablo Duque Cañas, PhD Universidad Nacional de Colombia. Bogotá, Colombia

Germán Darío Correal Pachón, MSc Universidad Católica de Colombia. Bogotá, Colombia

\section{TECNOLOGÍA, MEDIOAMBIENTE Y SOSTENIBILIDAD}

Luis Gabriel Gómez Azpeitia, PhD

Universidad de Colima. Colima, México

Luis Carlos Herrera Sosa, PhD

Universidad Autónoma de Ciudad Juárez, México

COMité CIENTífICO

Jorge Grané del Castillo, MSc Universidad de Costa Rica. San José, Costa Rica

Javier Peinado Pontón, MSc Pontificia Universidad Javeriana. Bogotá, Colombia

Jorge Alberto Villamizar Hernández Universidad Santo Tomás. Bucaramanga, Colombia

Augusto Forero La Rotta, MSc Universidad Católica de Colombia. Bogotá, Colombia Luis Álvaro Flórez Millán, MSc Universidad Católica de Colombia. Bogotá, Colombia

Elvia Isabel Casas Matiz, MSc Universidad Católica de Colombia. Bogotá, Colombia 


\section{Contenido}

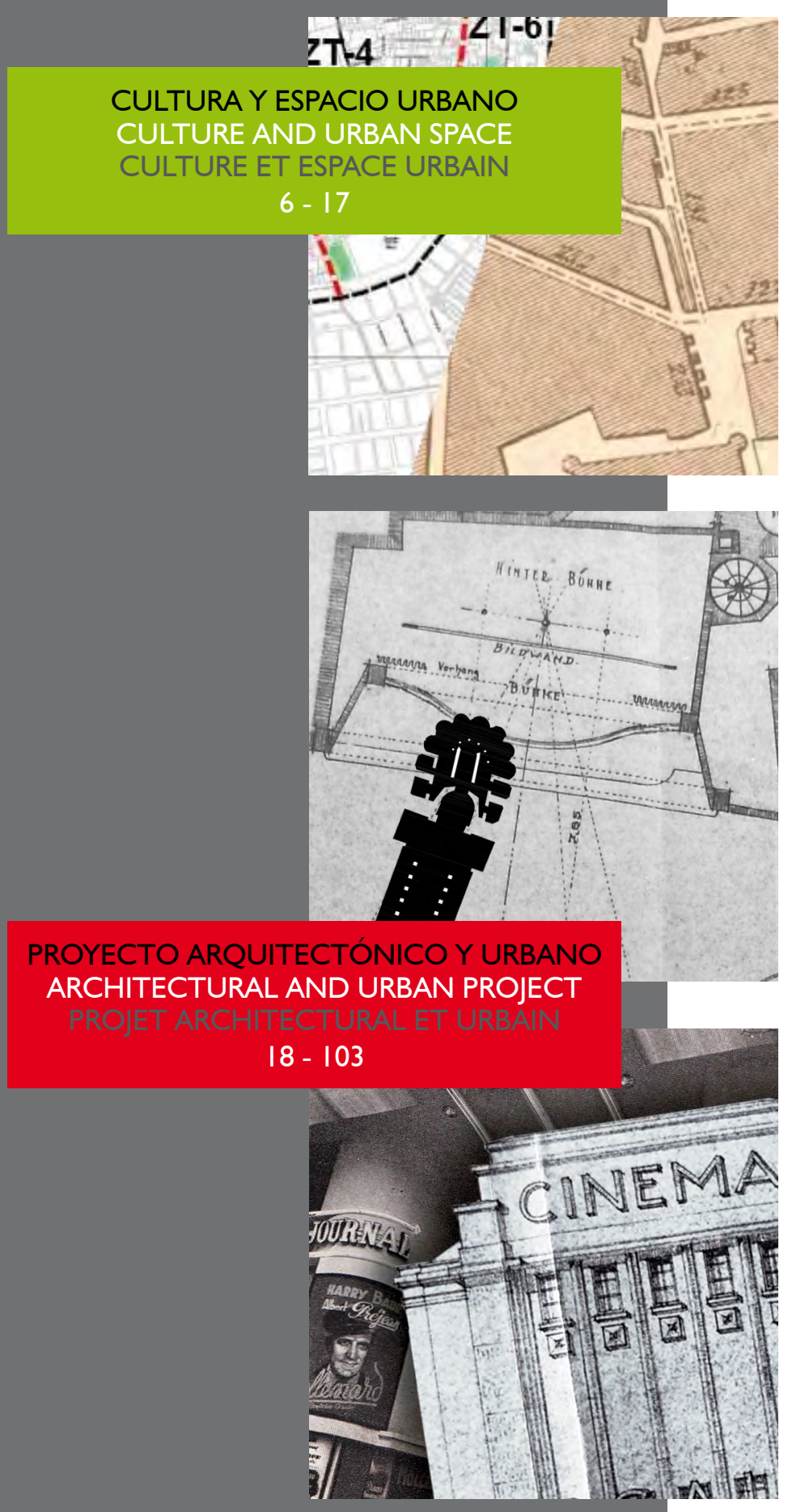

BARRIOS ALTOS: CARACTERIZACIÓN DE UN CONJUNTO DE BARRIOS TRADICIONALES EN EL MARCO DEL CENTRO HISTÓRICO DE LIMA

ANGIE SHIMABUKURO

TEATROS DE PAPEL I765-1860

¿CONSTRUCCIÓN DE UN MODELO “A LA FRANCESA"?

MARIBEL CASAS-CORREA

«ELDORADO» À LA FRANÇAISE OU À L'ALLEMANDE?

UNE ÉTUDE COMPARÉE DES CINÉMAS DE STRASBOURG

SHAHRAM HOSSEINABADI

SALAS DE CINE EN PUBLICACIONES DE ARQUITECTURA DE LOS AÑOS TREINTA

UNA MIRADA AL CASO DE LOS CINÉAC

ANDRÉS ÁVILA-GÓMEZ

PRODUCTION THÉORIQUE ET DIFFUSION

DES MODÈLES

De L'ÉCOLE PolyteChNIQUe À l'ÉCOLE des BEAUX-ARTS (I802-1967)

AMANDINE DIENER

ARQUITECTOS LATINOAMERICANOS EN LA ÉCOLE DES BEAUX-ARTS DE PARÍS EN EL SIGLO XIX

LUIS MANUEL JIMÉNEZ-MADERA

\section{EVANGELIZACIÓN Y PRECARIEDAD}

LA ARQUITECTURA RELIGIOSA SIN CORPORACIONES

NI ACADEMIAS EN LA NUEVA GRANADA

LUCÍA ARANGO-LIÉVANO

POUR UNE HISTOIRE DE LA TRANSFORMATION DES ÉDIFICES

COMPOSER AVEC LA PRÉEXISTENCE

LAURE JACQUIN

UNA MIRADA A LAS PUBLICACIONES EN LENGUA FRANCESA

BIBLIOGRAFÍA SELECTA: 2000-20 I 5

ANDRÉS ÁVILA-GÓMEZ

ESTUDIO DE LOS IMAGINARIOS SOCIALES URBANOS DESDE LAS PRACTICAS PEDAGOGICAS

FABIÁN ADOLFO AGUILERA-MARTíNEZ

PAULA ALEJANDRA VARGAS-NIÑO

NATALIA ISABEL SERRANO-CRUZ

María CAMILA CASTELLANOS-ESCobar

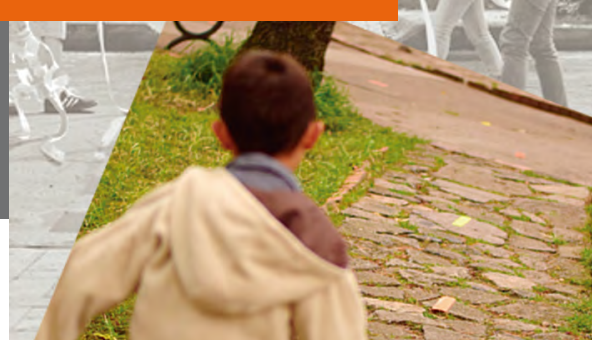




\section{PERSPECTIVES CROISÉES SUR LE DOCTORAT EN ARCHITECTURE}

Jean-Philippe Garric'

Université Paris I Panthéon-Sorbonne. París (Francia)

MOTS CLÉS : Histoire de l'architecture, recherche architecturale, formation doctorale, histoire culturelle, transfert culturel

Le choix de la revue d'architecture de l'Universidad Católica de Colombia de publier un numéro consacré au doctorat en architecture et en histoire de l'architecture en France, à partir d'une sélection de travaux réalisés par de jeunes chercheurs latino-américains, français, ou étrangers vivants en France, donne corps de façon originale et inédite à une réalité internationale qui n'est pas nouvelle, mais qui ouvre aujourd'hui de nouvelles perspectives.

Dans un panorama universitaire mondial de plus en plus multipolaire, le modèle universitaire français, qui continue de développer une alternative au modèle nord-américain dominant, regarde ses échanges avec les mondes universitaires hispaniques et lusophones, comme prioritaires. Pour autant, I'origine de cette publication n'est en rien institutionnelle, reflétant une réalité humaine et un parti pris subjectif, elle résulte au contraire d'une expérience au quotidien : fruit des rencontres et des échanges entre doctorants, qui ont pris corps dans le contexte de séminaires doctoraux, de journées d'études ou de façon plus informelle, et de la détermination d'Andrés Ávila Gómez à donner lieu à ces connivences et à ces pratiques intellectuelles convergentes, ou du moins confrontées. Il est remarquable que les auteurs invités à participer, architectes de formation à une seule exception près, abordent les domaines de l'architecture et de la ville, du patrimoine et de l'histoire, suivant des démarches qui relèvent très majoritairement de l'histoire culturelle et qui s'en revendiquent. II faut sans doute se réjouir de voir ainsi des étudiants disposant par ailleurs de tous les outils pour aborder et analyser les édifices, dans leur conformation physique et leur organisation spatiale, choisir d'interroger leur discipline du point de vue de sa relation à la société et ne pas s'enfermer dans des approches formelles ou internalistes.

I Architecte DPLG (École d'Architecture de Toulouse).

Pensionnaire de l'Académie de France à Rome.

DEA Projet architectural et urbain (Paris 8 / Ensa Paris-Belleville)

Doctorat en Urbanisme et Aménagement (Université Paris 8, directrice : Françoise Choay). HDR Habilitation à diriger les recherches (Université Paris-Est, tuteur : Jean-Louis Cohen). Professeur d'Histoire de l'Architecture à l'Université Paris I Panthéon-Sorbonne. Directeur du Labex CAP : Laboratoire d'Excellence Création, Arts et Patrimoines. Directeur des collections d'architecture des éditions Mardaga.

Projet d'exposition actuel : *Charles Percier (1764-1838): Revolutions in Architecture and Design*, Bard Graduate Center Gallery - New York, November 2016 - February 2017 Publications:

(2014) Vers une agritecture : architecture des constructions agricoles (1789-1950), Bruxelles : Mardaga.

(2012) Percier et Fontaine, les architectes de Napoléon, Paris : Belin.

(2006) La Chapelle expiatoire, Itinéraire du patrimoine, Paris : Editions du patrimoine.

(2004) Recueils d'Italie, les modèles italiens dans les livres d'architecture français, Liège : Mardaga.

jean-philippe.garric@univ-parisI.fr
La formation des modèles et leur diffusion à travers I'enseignement et la presse est abordée par Maribel Casas Correa à propos des théâtres français entre le Siècle des Lumières et le Second Empire ; par Amandine Diener à propos de la formation des architectes en France de la Révolution à la veille de Mai 68 ; puis, enfin, par Andrés Ávila Gómez à propos des salles de cinéma dans des publications d'architecture des années 30. Tandis que I'organisation des cadres professionnels de la production du bâti, dans le contexte spécifique de la Nueva Granada coloniale, est au cœur de l'étude de Lucía Arango Liévano, qui ouvre aussi à l'autre grand thème présent dans ces articles : celui des transferts culturels qui se développent entre nations européennes, comme dans le cadre inégal de relations de domination ou d'échanges asymétriques entre centre et périphérie.

La contribution de Shahram Hosseinabadi, à propos des cinémas strasbourgeois produits successivement sous domination allemande puis française, se range dans la première catégorie, permettant de discuter à la fois de la construction et de l'affirmation de réalités nationales et de leur hybridation dans l'Europe du XXe siècle. Celle de Luis Manuel Jiménez Madera, sur les élèves architectes latino-américains de l'École des Beaux-Arts de Paris au XIX ${ }^{\mathrm{e}}$ siècle, appartient au contraire à la seconde catégorie. Bien qu'ils soient plus directement tournés vers des enjeux contemporains du projet architectural et de l'aménagement urbain en contexte patrimonial, les textes de Laure Jacquin et d'Angie Shimabukuro n'échappent pas à cette double thématique culturelle et internationale. La première inscrit clairement sa démarche dans un questionnement diachronique, qui interroge le passé à l'aune de questions actuelles, pour informer en retour le présent. La mutation qu'elle vise, celle de l'intervention contemporaine dans les monuments historiques, est sous-tendue par l'internationalisation d'un regard patrimonial longtemps déterminé par des cadres nationaux. La seconde, qui s'intéresse au Centre historique de Lima étudie à l'inverse la façon dont des injonctions patrimoniales internationales se projettent et s'adaptent à une réalité locale.

Ainsi, ce numéro décrit une actualité de la recherche architecturale en France, qui est marquée par une attention partagée aux méthodes de I'histoire culturelle, comme aux transferts internationaux. Le panorama original qu'il propose permet de prendre date, en donnant corps à I'hypothèse stimulante d'une réalité internationale, à la fois par ses objets, par ses méthodes et par ces acteurs. 


\title{
POUR UNE HISTOIRE DE LA TRANSFORMATION DES ÉDIFICES
}

\author{
COMPOSER AVEC LA PRÉEXISTENCE
}

\section{Laure Jacquin}

Université Paris-Est, París (Francia)

Laboratoire IPRAUS - Institut Parisien de Recherche : Architecture, Urbanistique, Société. (ENSA Paris-Belleville)

Jacquin, L. (2015). Pour une histoire de la transformation des édifices. Composer avec la préexistence. Revista de Arquitectura, $I 7(\mathrm{I})$

92-100. doi: 10.14718

RevArq.2015.17.I.9

\section{(c) (1) $\odot($ BY NC SA}

http://dx.doi.org/10.14718/ RevArq. 2015.17.1.9
Baccalauréat Lycée Chateaubriand, Rome, mention assez bien

Diplôme d'État d'Architecte à l'ENSA Marseille-Luminy, et Habilitation à la Maîtrise d'œuvre en son Nom Propre à l'ENSA Marselle-Luminy Master Recherche à l'ENSA Paris-Belleville

Doctorante en Architecture, I'Université Paris-Est au sein du laboratoire de l'IPRAUS (ENSA Paris-Belleville). Enseignement à l'ENSA Paris-Belleville

(20I4) Licence I TPCAU (théorie et pratique de la conception architecturale et urbaine) ; Depuis 20I4, Chargée de Travaux Dirigés d'analyse urbaine, L2; (20I3) Séminaire Master I et 2 « Patrimoine et Projet ». Enseignement à l'ENSA Paris Val-de-Seine

(20I3) Chargée de TD d'analyse urbaine, LI, Enseignants référents : Elisabeth Essaian, Xavier Malverti; et Chargée de TD de cartographie et géographie, L3, Enseignants référents : Aleth Picard, Xavier Malverti

Distinctions

Allocation d'Études spécialisées, Ministère de la Culture et de la Communication, 201 I-2014.

Bourse, Fondation pour les Monuments historiques, 2014

Publications

(20/4), "Conserver et mettre en valeur les fortifications de montagne, l'exemple de la restauration du Castelgrande et l'aménagement de la piazza del Sole à Bellinzona » dans les actes du colloque Fortifier la montagne tenu à Toulouse les I2-I4 novembre 20 I4, presses universitaires de Toulouse le Mirail.

(20|3), «Représenter le projet dans l'existant » in Revue Monumental, numéro spécial « Architecture contemporaine et monuments historiques ", Éditions du patrimoine, Paris, semestriel I, juin 2013, p. 33-34

(2008), Piscina sull'isola dans « Bauen Am Rein », sous la direction de Peter Zumthor

jacquin.laure@hotmail.fr

PARA UNA HISTORIA DE LA TRANSFORMACIÓN DE EDIFICIOS

COMPONER CON LA PREEXISTENCIA

\section{RESUMEN}

La intervención arquitectónica sobre lo existente se ha convertido, al día de hoy, en un nuevo paradigma de proyecto, demandando desde la historia de las prácticas arquitectónicas, una nueva mirada que se nutra de los intereses actuales. A partir de la hipótesis según la cual, las prácticas antiguas pueden proveer, aún hoy en día, herramientas para pensar el proyecto, en este artículo se propone el análisis de dos edificios notables — la iglesia de Saint-Denis (Francia) y el Temple de Malatesta (Italia) _ desde un enfoque que privilegia la relación establecida entre lo antiguo y lo nuevo en el proyecto arquitectónico, y cuyo interés se centra en la evolución de las problemáticas y los desafíos en dicho campo, así como en el análisis de las posiciones de los arquitectos. Se abordan aquí dichos aspectos, desde la perspectiva de la relación entre lo antiguo y lo nuevo en el proyecto, y de sus etapas de transformación, traducidas y puestas en evidencia a través del dibujo, con el objetivo de reposicionar en un marco cronológico amplio, la historia de la ejecución del proyecto en lo existente.

PALABRAS CLAVE: arquitectura religiosa, composición arquitectónica, Leon-Battista Alberti, monumentos históricos, patrimonio, restauración, teoría arquitectónica.

\section{FOR A HISTORY OF THE TRANSFORMATION OF BUILDINGS}

DEALING WITH THE EXISTING

\section{ABSTRACT}

The architectural intervention that exists has become, today, a new paradigm of the project, demanding from the history of architectural practices, a new look that draws on existing interests. From the hypothesis that ancient practices can provide, even to this day, tools to think the project, in this article the analysis of two notable buildings is proposed - the church of Saint-Denis (France) and the Temple in Malatesta (Italy) from an approach that favors the relationship established between the old and the new in architectural projects, whose focus is on the evolution of the issues and challenges in this field, as well as the analysis of the architects' positions. These aspects are discussed here from the perspective of the relationship between the old and new in the project, and its transformation stages, translated and brought out through drawing, with the aim of repositioning in a broad time frame, the history of project execution in the existing one.

KEY WORDS: Religious architecture, architectural composition, Leon-Battista Alberti, historical monuments, heritage restoration, architectural theory.

\section{POUR UNE HISTOIRE DE LA TRANSFORMATION DES ÉDIFICES}

COMPOSER AVEC LA PRÉEXISTENCE

\section{RÉSUMÉ}

Au moment où l'intervention dans l'existant est devenue un paradigme de projet, l'histoire de ces pratiques architecturales demande à être envisagée avec un nouveau regard nourri des intérêts actuels. Partant de l'hypothèse que les pratiques anciennes peuvent fournir des outils pour penser le projet aujourd'hui, l'article propose d'analyser deux édifices remarquables -L'église de Saint-Denis (France) y Le Temple de Malatesta (Italie)- du point de vue de la relation établie entre l'ancien et le neuf dans le projet réalisé par l'architecte ; |'intérêt étant centré sur l'évolution des problématiques et des enjeux dans ce domaine et analyse la position des architectes. Ces aspects sont abordés en se plaçant sous l'angle du projet et du rapport entre le neuf et l'existant, que l'on traduit par le biais du dessin qui met en évidence la relation entre les deux, ainsi que les étapes de la transformation. II vise, ainsi, à replacer l'histoire de la fabrication du projet dans l'existant dans une perspective chronologique ample. MOTS CLÉS : Architecture religieuse, composition architecturale, Leon-Battista Alberti, monuments historiques, patrimoine, restauro, théorie architecturale. 


\section{INTRODUCTION}

Cet article est issu d'un travail de master recherche "Projeter dans l'existant" dont I'objectif était la préparation de la thèse en cours qui porte sur l' "Architecture contemporaine dans les Monuments historiques en France (1964-2012). Projets et polémiques " effectuée sous la direction de Jean-Philippe Garric et financée par le Ministère de la Culture et de la Communication, et la Fondation Pour les Monuments Historiques.

De nos jours, une part conséquente de la commande architecturale dans les grandes villes européennes chargées d'histoire porte sur des transformations d'édifices anciens. On constate ainsi, que la notoriété de certains architectes repose sur des opérations de ce type. Jacques Herzog et Pierre de Meuron ont été reconnus par la critique architecturale suite à l'opération de la Tate Modern à Londres puis à celle de la Caixa à Madrid ; Anne Lacaton et Jean-Philippe Vassal après leur intervention à la Tour Bois-le-Prêtre ; la transformation de I'Opéra de Lyon est considérée comme une des œuvres majeures de Jean Nouvel. Cette évolution accompagne un regain d'intérêt pour la ville historique ${ }^{1}$ qui se manifeste depuis le début des années 1960, notamment avec des courants comme celui de la Tendenza. De ce point de vue le projet dans I'ancien répond à une sensibilité actuelle.

Dans le domaine de la restauration, les Architectes en Chef des Monuments Historiques français, qui jusqu'au début des années 1960 appliquaient les principes élaborés au XIXe siècle par le Service des Monuments Historiques ${ }^{2}$ (restauration dite à la française ou stylistique), commencent à s'en écarter et revendiquent une posture de créateurs ${ }^{3}$.

On observe ainsi une rencontre entre deux milieux qui étaient jusque-là clairement divisés (restaurateurs et créateurs), certains les architectes choisissant de créer dans des édifices existants, tandis que les architectes formés à la restauration revendiquent la possibilité de créer dans les Monuments.

À cela s'ajoute la complexité des statuts des architectes français concernés, qui souligne la nécessité d'intégrer et d'harmoniser l'enseignement du projet, de l'histoire dans les édifices existants dans le cursus les études d'architecture. En effet, à côté des Architectes en Chef des Monu-

1 Voir Rossi, Aldo (2004)

2 Structure étatique créée en 1830 dans le but de recenser, conserver et restaurer les Monuments de la Nation.

3 Comme Pierre Prunet, Bruno Decaris, ou encore Francesco Flavigny. ments Historiques ${ }^{4}$, qui sont censés se charger de la restauration des grands Monuments nationaux, on trouve maintenant des architectes du patrimoine $^{5}$, des architectes titulaires d'un DSA ${ }^{6}$ patrimoine, qui s'occupent de restauration de Monuments classés ou non, et des architectes $\mathrm{DPLG}^{7}$ ou $\mathrm{HMNOP}^{8}$, qui sont susceptibles eux aussi de projeter dans l'existant bien que n'ayant pratiquement pas bénéficié d'une formation spécifique dans ce domaine particulier, ni sous l'angle du projet, ni sur le plan technique. Face à cette situation, depuis peu, on voit se mettre en place en cycle master pour former les architectes au projet dans l'existant.

Il y a certes là un phénomène de mode, mais la situation amène à s'interroger, au-delà des notions de restauration, sur les références architecturales qui sous-tendent les projets, sur les principes et les attitudes adoptés par les architectes, et sur les conséquences de ce renouvellement des pratiques. La multiplication des interventions dans l'existant pose de nombreuses questions allant de la compétence des intervenants au choix des outils à utiliser pour représenter un projet dans l'existant, en passant par les critères adoptés pour choisir ce que l'on va conserver et pour vérifier le caractère conservateur de l'intervention. De cette réflexion émerge une piste qui oriente vers I'histoire des pratiques pour interroger la fabrication du projet architectural dans l'existant.

4 Les Architectes en Chef des Monuments Historiques (ACMH) sont formés à l'École de Chaillot et recruté par voie de concours public. Ils sont fonctionnaires de l'Etat mais travaillent en tant qu'indépendants et sont rémunérés par honoraires. Aujourd'hui leur fonction décline mais à l'origine ils s'occupaient de tous les Monuments Historiques classés qu'ils soient publics ou privés.

5 Les architectes du patrimoine existent depuis la réforme de 2005 qui cadre les niveaux d'étude et de diplôme. Ils sont titulaires d'un DSA patrimoine obtenu après avoir suivi l'enseignement de Chaillot. Si 'lon devait classer hiérarchiquement les architectes par compétence légale vis-à-vis des Monuments, les architectes en chef ont le plus de pouvoir, suivis par les architectes du patrimoine. Les architectes titulaires d'un DSA patrimoine ont légalement la même qualification que les architectes du patrimoine mais ils ont suivi un autre cursus de DSA que celui de Chaillot.

6 Le DSA est un Diplôme de Spécialisation en Architecture. Dans le champ patrimoine, ce titre permet d'intervenir sur des édifices inscrits, sur du patrimoine industriel ainsi que sur des Monuments Historiques à condition de pouvoir justifier de 10 ans d'expérience.

7 DPLG : Architecte diplômé par le gouvernement, ancien titre des architectes, donné jusqu'en 2005. Il a été remplacé depuis par le titre d'ADE/HMONP (Architecte diplômé d'Etat habilité à la maitrise d'œuvre en nom propre).

8 HMONP : Habilité à la maitrise d'œuvre en nom propre, titre remis à al sixième année d'études d'architecture en France, suite à l'obtention du diplôme d'architecte d'Etat. Le titre d'HMONP est obligatoire pour pouvoir exercer en France et s'inscrire à l'Ordre des Architecte.

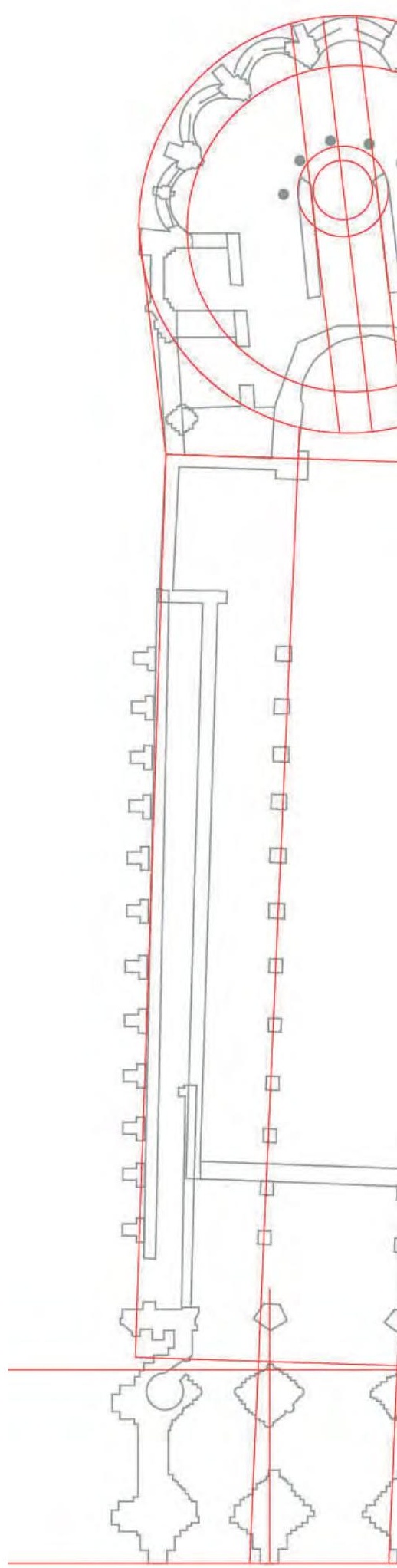




\section{MÉTHOdologie}

L'étude développée ici s'est donné pour objectif de revisiter l'histoire des pratiques au regard du projet dans l'ancien. C'est en confrontant la notion de composition à des édifices majeurs de I'histoire de l'architecture que l'on propose ici de traiter la question. Deux constructions emblématiques de l'histoire de l'architecture seront étudiées à partir de la notion de composition, pour tenter de comprendre si elle peut conduire à un renouvellement des références sur lesquelles reposent l'enseignement et la pratique du projet. En effet, les pratiques de transformation des édifices sont présentes dans l'histoire depuis l'Antiquité, mais les positions et les attitudes par rapport à cette question ont évolué sous l'influence d'évènements importants ou de mutations culturelles et techniques, tels que la Révolution française et l'industrialisation de la construction, qui ont modifié la relation au passé et à la matière des édifices.

Le thème de la restauration a fait l'objet de réflexions dès le début du XIXe siècle et les positions adoptées tant par les théoriciens que par les praticiens ont profondément évolué depuis cette date. Dans le cadre de cet article, on se limitera à signaler uniquement les personnalités et les évènements les plus marquants dans ce domaine. Eugène Viollet-leDuc (Viollet-le-Duc, 1800) joua au départ un rôle déterminant en imposant le dogme de la restauration stylistique, une attitude qui fut rapidement contestée par certains. La critique devint constructive et efficace avec l'intervention de Camillo Boito (2000) et de Cesare Brandi (2000) qui s'opposent à la falsification des monuments et prônent une restauration philologique. Les idées du premier sont présentes dans la Charte de Venise, à laquelle le second mit directement la main en 1964.

Face à la densité des publications portant sur la restauration, on constate que les réalisations architecturales et les processus techniques de composition avec l'existant n'y sont que rarement traités et généralement de manière fragmentaire. Une tentative en ce sens a été faite dans le cadre d'un ouvrage collectif, Verso una storia del restauro, dirigé par Stella Casiello et Roberto Pane (Casiello, 2008). Cet ouvrage nous intéresse particulièrement ici, parce qu'il replace la pratique du « restauro » (terme qui, en Italie, recouvre un sens bien plus large que celui du mot restauration) dans une perspective historique ample, débordant par rapport au débats des théoriciens en intégrant la période précédant l'institutionnalisation des pratiques de restauration qui a eu lieu au XIXe siècle.

Dans ce recueil, constitué de neuf articles, chacun des auteurs retrace l'évolution des attitudes adoptées face à la réutilisation de bâtiments anciens en examinant des exemples de transformations d'édifices ou d'objets. Chaque fois, une attention particulière est portée au contexte histo- rique et artistique de la période considérée, au parcours de l'architecte, ainsi qu'à ses écrits. Les textes s'appuient parfois sur des plans et souvent sur des illustrations des édifices, des photographies, des monnaies, des croquis d'époque... Cet ouvrage donne un aperçu de l'évolution des attitudes dans le temps en ayant pour fil conducteur I'histoire. En revanche, I'analyse des transformations y occupe une place marginale. Les propos développés par les auteurs restent focalisés sur des questions historiques plutôt que sur la composition architecturale et l'analyse se traduit sous la forme d'une narration accompagnée de rares supports graphiques et visuels. En contrepartie, les travaux de ces auteurs fournissent le support utile, ainsi que des pistes de réflexion stimulantes dans la perspective d'une analyse plus spécifiquement architecturale.

Les deux cas étudiés dans cet article précèdent la constitution théorique de la notion de patrimoine, de conservation et de restauration. En cela ils peuvent servir de support à une réflexion concernant spécifiquement le projet avec un édifice existant comme composition composite.

Ces deux interventions sont l'extension de l'église Saint-Denis par l'Abbé Suger en 1135 et la rénovation du temple de Malatesta à Rimini par Leon-Battista Alberti en 1443. Ces deux projets ont pour raison d'être l'encadrement et la mise en valeur de tombeaux, et, malgré cette similitude dans les objectifs, les architectes ont donné des réponses spatiales très différentes. Ainsi nous verrons comment, à Saint-Denis, l'ensemble de la nouvelle composition se fait dans la continuité avec I'ancien, alors qu'au temple de Malatesta elle se fait dans la confrontation et le contraste avec l'ancien.

\section{RÉSULTATS}

\section{COMPOSER DANS LA GÉOMÉTRIE DE L'EXISTANT : L'ÉGLISE DE SAINT-DENIS (FRANCE)}

L'agrandissement de l'église Saint-Denis en France a été effectué par l'abbé Suger, alors responsable de la congrégation, entre 1135 et 1148. Les travaux sont entrepris durant une période de grande prospérité de la congrégation attachée à ce lieu de culte, et la situation économique favorable permet des réalisations de grande ampleur. La transformation a pour but de répondre à "I'affluence des fidèles", en mettant l'accent sur la sacralité du lieu, déjà largement reconnue.

Rappelons que cette réalisation est considérée aujourd'hui comme la première expression du style gothique dans un édifice religieux, et occupe une place importante dans l'histoire de l'architecture ${ }^{9}$.

9 Sur cet édifice, voir: Brankovic, Branislav (1990); Summer Mc Knight, Crosby (1953); Summer Mc Knight, Crosby (1987); Wyss, Michael (sous la direction de) (1996). 

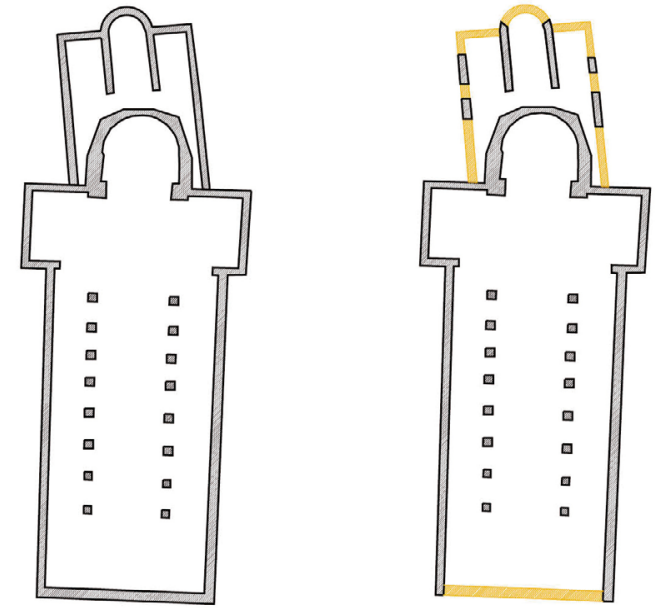

2
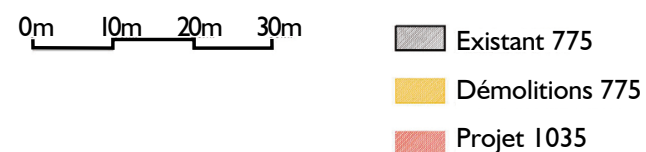

\section{Aperçu historique}

Le sanctuaire existant avant l'intervention de l'Abbé est de petites dimensions. Il se compose de deux édifices imbriqués mais désaxés l'un par rapport à l'autre : une église carolingienne, datant de 775, orientée au Sud-est et la chapelle d'Hilduin, construite en 832, orientée à l'Est. L'église carolingienne, de plan cruciforme, possède un chœur en forme d'abside et une nef bordée de part et d'autre de collatéraux. Outre le fait qu'ils sont désaxés, les deux corps de bâtiment se trouvent à des niveaux différents, l'église étant de plain-pied avec le sol extérieur alors que la chapelle est semi-enterrée. Par son intervention, l'abbé Suger ajoute une troisième strate à l'édifice. (Illustration 1)

\section{Analyse}

Après l'exécution de réparations portant sur les structures qui seront conservées, la construction débute en 1140 avec l'adjonction d'un nouveau narthex, suivie par celle d'un nouveau chœur en 1144, par celle du transept et de la nef en 1145 et, enfin, en 1148, par l'érection de la tour sud. Une partie du projet de Suger reste inachevée à sa mort, mais son œuvre est poursuivie par ses successeurs. Aujourd'hui, le narthex et le chœur que Suger fit réaliser sont encore intacts, tandis que la nef a été largement remodelée ultérieurement. Les raccords entre neuf et ancien peuvent toutefois être encore bien observés dans la crypte de la chapelle, sous le chœur actuel. (Illustration 2)

L'opération menée par Suger entraîne des démolitions ponctuelles permettant l'élargissement de l'espace de l'église. La façade de l'église carolingienne est déposée ainsi qu'une partie conséquente de l'enveloppe de la chapelle. Ces démolitions permettent de mieux les englober dans la nouvelle église.
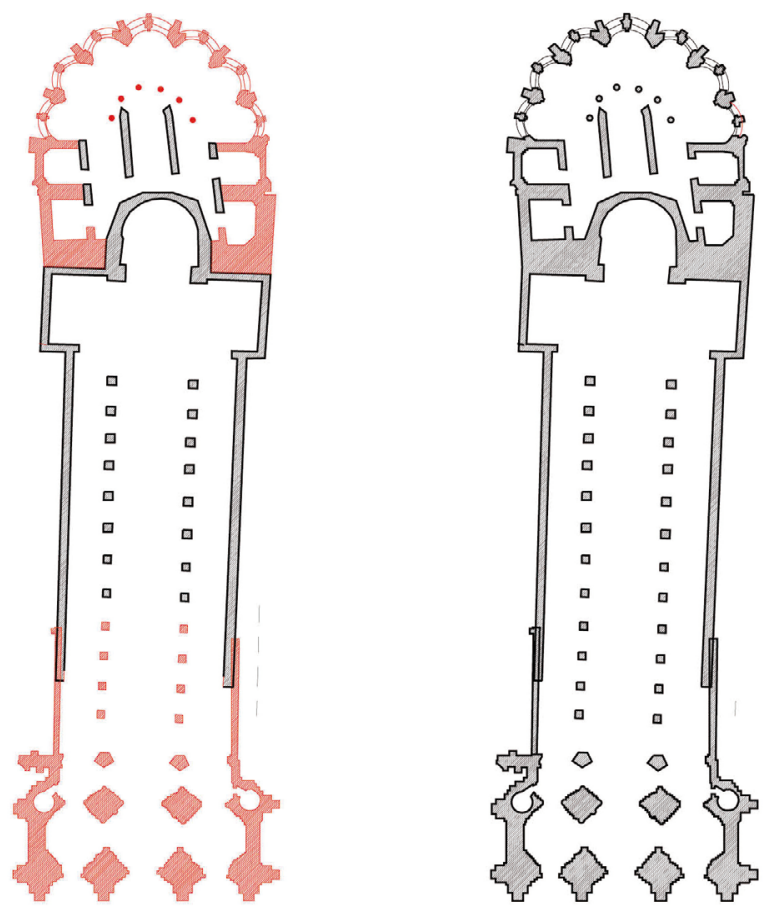

Illustration 1. Plans des étapes de transformation de l'église Saint-Denis Source: Dessin de l'auteur d'après les relevés de Crosby Summer Mc Knight.

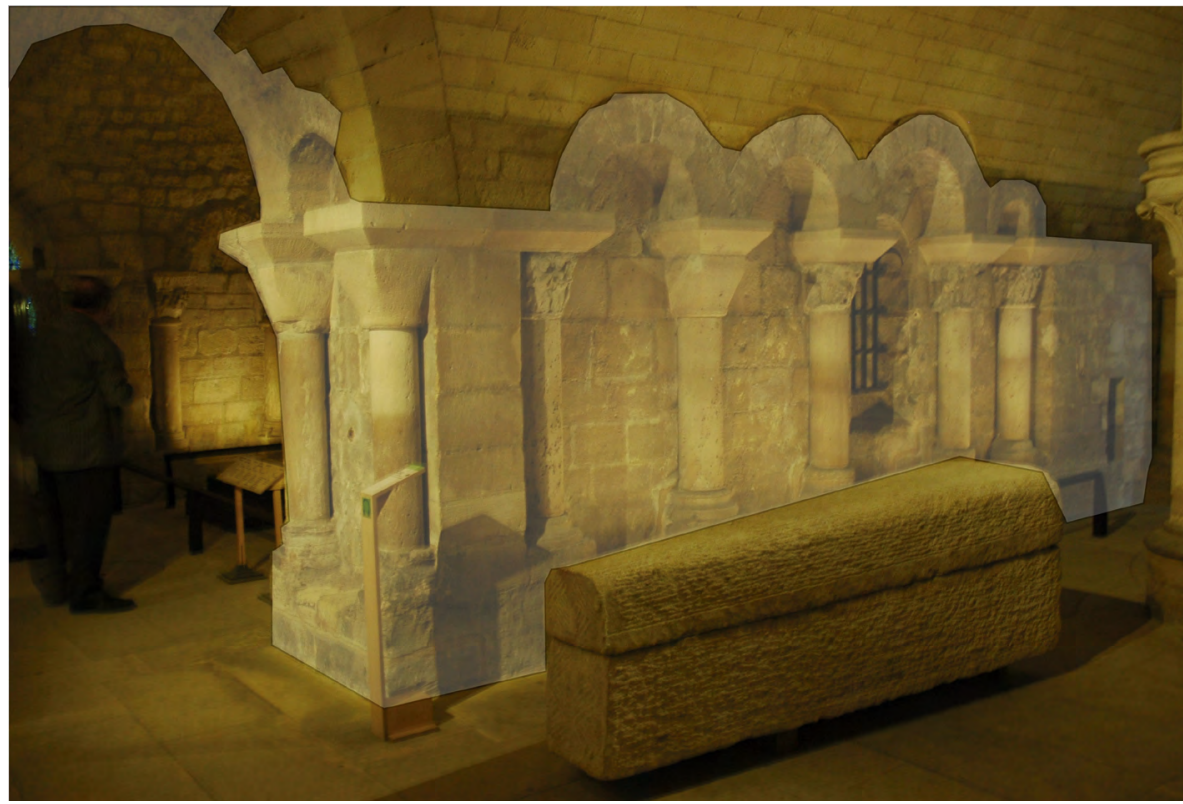

Le plan de cette dernière se développe en longueur : l'accès se fait par un narthex, qui se prolonge par une nef flanquée de bas-côtés et se termine par un chœur circulaire en hauteur par rapport au niveau du sol de la nef. La structure du chœur est fine et élancée, laissant entrer la lumière par de larges baies munies de vitraux. Le chœur et les parties conservées de la chapelle d'Hilduin forment un nouvel ensemble homogène sur deux niveaux : le niveau bas, dans lequel se trouvent les murs conservés de la chapelle et le niveau haut, surélevé par rapport à la nef qui définit le déambulatoire du chœur.

\section{Composition par la géométrie}

Si dans cet édifice les structures nouvelles s'articulent harmonieusement avec les éléments anciens au sein d'une composition qui apparaît comme unitaire, c'est grâce au rôle que l'on a fait jouer à la géométrie dans la conception du projet.
(A) Illustration 2. Raccord neuf-ancien dans la crypte

Source : Photographie de l'auteur. 
$\nabla$ Illustration 3. Forme et géométrie dans la relation neuf-ancien

Source : dessins de l'auteur d'après les relevés de

Crosby Summer Mc Knight.

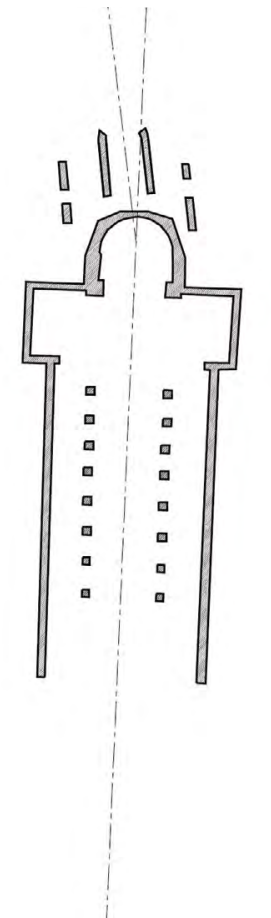

Composition, rapport de géométrie
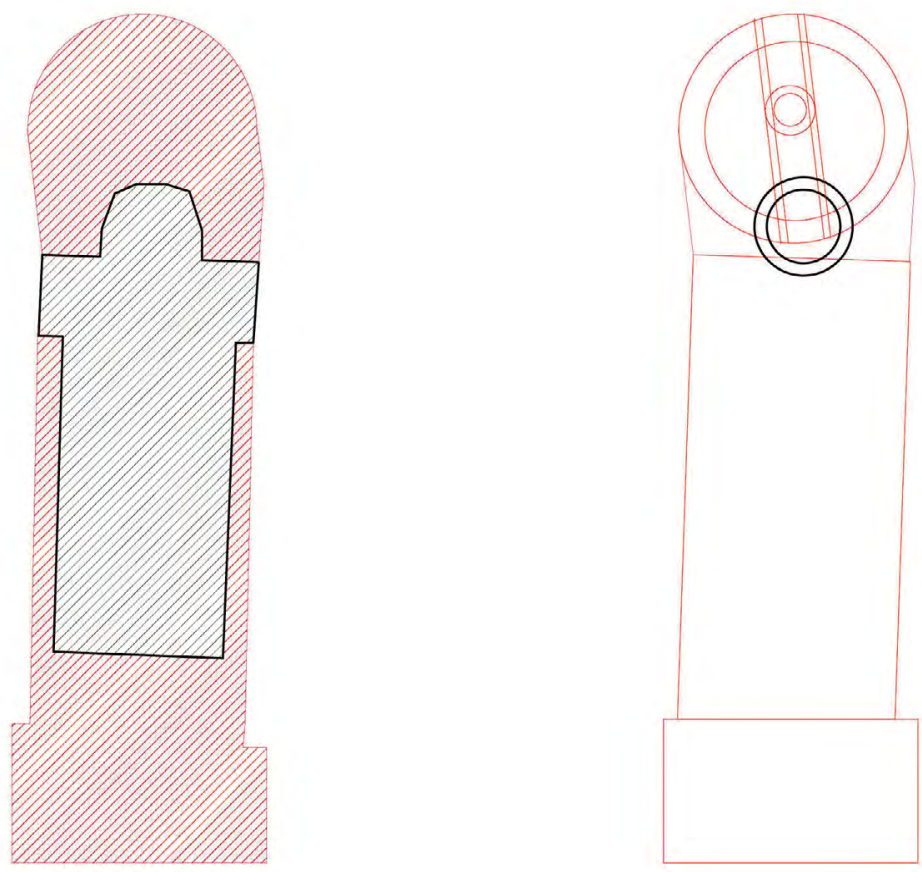

Rapport neuf ancien
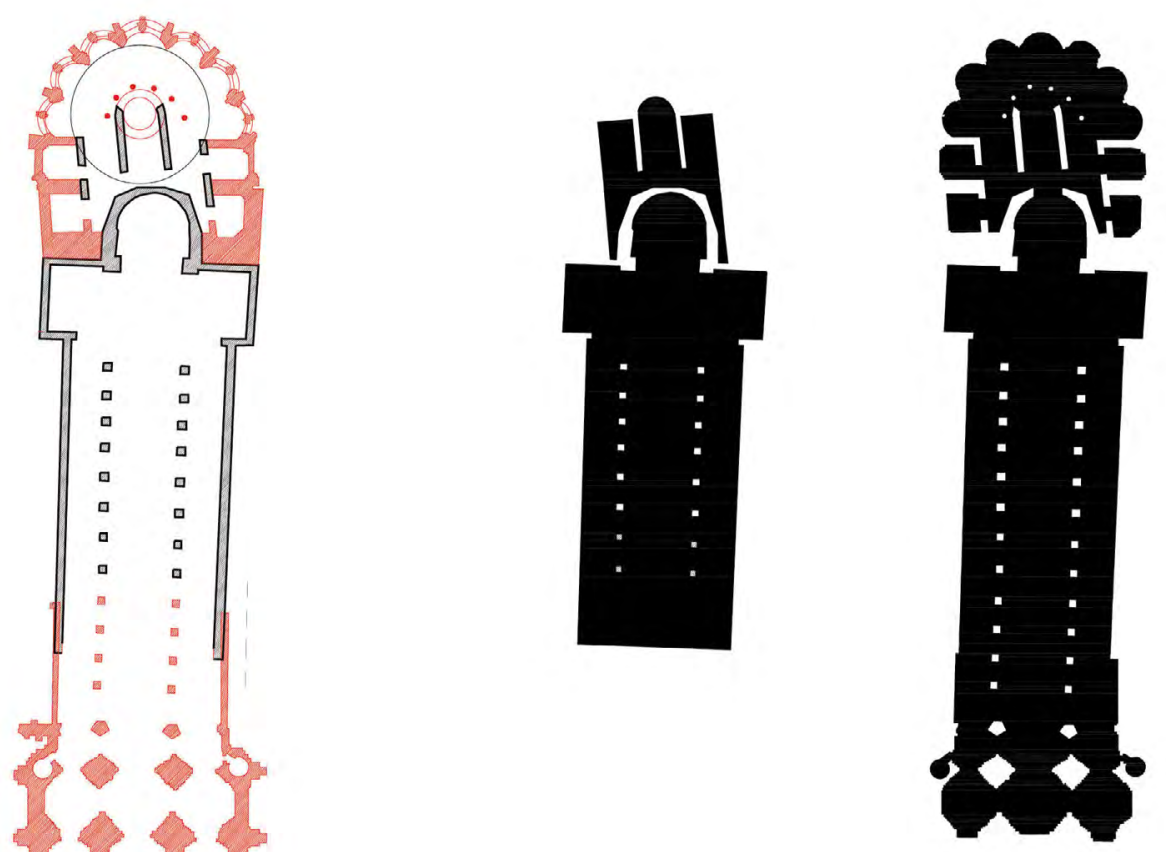

Espace intérieur

(A) Illustration 4. Axes et rapport plein vide dans la composition

Source : dessins de l'auteur d'après les relevés de Crosby Summer Mc Knight.
L'orientation du chœur construit par Suger reproduit celle de la chapelle de l'Hilduin, qui est intégrée au nouvel ensemble. Le narthex et le prolongement de la nef, en revanche, adoptent l'orientation de l'église carolingienne. Les irrégularités dans l'arc de cercle formé par le chœur de la chapelle se retrouvent dans l'adjonction. Le décalage des axes, à partir duquel Suger organise sa composition, n'est perceptible qu'en plan et constitue l'élément qui contribue à assurer l'homogénéité de l'ensemble. (Illustration 3)

\section{Typologie, morphologie}

Au plan inférieur, qui correspond à celui de la chapelle de l'Hilduin, Suger conserve une partie des murs antérieurs et y adjoint des chapelles rayonnantes sur le pourtour, en élargissant ainsi sa forme semi-circulaire. Au niveau supérieur, la structure de la façade du chœur est constituée de piliers largement espacés qui définissent de grandes baies convexes laissant entrer la lumière de manière spectaculaire et innovante : le vide prend le pas sur le plein. (Illustration 4)

Les murs latéraux, ainsi que les colonnes de la nef carolingienne, sont prolongés vers le nord sur quatre travées, en reproduisant les proportions des éléments existants. Le narthex est défini par une structure épaisse de style gothique constituée de piliers placés dans l'alignement des colonnes de la nef dont ils se distinguent par leurs dimensions et leur style architectural. L'épaisseur des piliers du narthex est imposante en rapport à l'épaisseur des colonnes existantes de la nef. Au fur et à mesure que les piliers du narthex s'approchent des colonnes de la nef, ils s'affinent pour assurer une transition visuelle avec les colonnes anciennes. 


\section{Matériaux, structure}

La nouvelle construction se fonde sur les restes anciens et les prolonge en élévation. II n'y a aucun souci de réversibilité de l'intervention, mais au contraire une volonté de d'assurer la pérennité des nouvelles structures.

La pierre calcaire employée pour l'ensemble des nouvelles constructions est la même que celle des constructions antérieures. Cette constante dans le choix des matériaux assure la liaison entre les éléments.

Ce matériau n'est pourtant pas traité de la même manière car la taille et les sections de la pierre sont nettement plus fines dans l'intervention de Suger. Cette différence de mise en œuvre est due à l'évolution des techniques, ainsi qu'à l'adoption de registres architecturaux (croisées d'ogive, arcs brisés) visant à ouvrir largement l'édifice à la lumière.

\section{Rapport au passé}

Bien que l'écart de temps qui sépare la construction des édifices existants de l'intervention de Suger est de trois cents ans pour la chapelle d'Hilduin et de quatre cents ans environ pour l'église carolingienne, on remarque que, dans cette intervention, tous les éléments portent à voir une forme de continuité dans la relation à l'architecture existante. À la fois dans les matériaux employés, dans la composition architecturale qui reprend les axes et orientations de l'existant que dans l'unité nouvelle proposée. Les styles architecturaux ne sont pas les mêmes, mais l'emploi des mêmes matériaux, la reprise des alignements de colonnes, de formes, d'axes de composition se présentent plutôt comme une évolution linéaire que comme une rupture ou une mise à distance avec le passé.

\section{Attitude architecturale}

L'entrée dans l'église est désormais articulée en trois séquences définies par l'espace et par la lumière : le fidèle pénètre dans le narthex qui le plonge dans l'obscurité puis, plus il s'avance dans l'église, plus la lumière s'intensifie pour atteindre son apogée dans le chœur. L'architecture éveille et alimente le sentiment de spiritualité à travers une illumination que rendent possible les nouvelles techniques de construction.

\section{Interroger le projet au regard de questionne- ments actuels}

Cette intervention ne peut pas être considérée comme réversible selon les critères actuels de la Charte de Venise (1964) dans la mesure où les ajouts font corps avec l'existant à tel point qu'ils ne peuvent être retirés. La nouvelle réalisation donne néanmoins la possibilité, à l'œil éveillé, de lire et de retrouver l'organisation et les caractéristiques des structures préexistantes. Elle est donc irréversible mais lisible.
Ce premier cas encourage à reconsidérer la querelle entre création et conservation sous un nouveau jour, car ici, création et conservation vont de pair. Aucun conflit ne s'instaure entre ce qui préexiste et ce qui est ajouté, le résultat de la transformation est un nouvel édifice fait de parties neuves et anciennes qui forment un nouvel ensemble. C'est par la géométrie et le travail sur les axes que l'ensemble trouve une cohérence. Dans cet exemple on peut donc observer un projet neuf qui se fabrique à partir de la logique des constructions existantes et dans la continuité avec celles-ci. On peut le comparer à la transformation du Castelgrande de Bellinzona (Suisse) où Aurelio Galfetti a adopté la même attitude.

\section{COMPOSER DANS LA CONFRONTATION AVEC L'ANCIEN : LE TEMPLE DE MALATESTA (ITALIE)}

Le deuxième cas étudié est celui de l'église San Francesco à Rimini, transformé en Temple de Malatesta par Léon-Battista Alberti (1404-1472), considéré comme « la personnalité la plus influente dans I'histoire de I'architecture de la Renaissance» (Casiello, 2008, p. 81). Parmi les études portant sur le Temple de Malatesta on citera celle que donne Franco Borsi (1980) dans sa monographie consacrée à l'architecte, qu'il caractérise comme étant son œuvre majeure. Dans son analyse, l'auteur se concentre sur la composition de la façade neuve d'Alberti (insistant sur la référence de l'architecte aux modèles antiques) ainsi que sur la restitution du projet d'ensemble (comprenant la façade principale et la coupole), mais il porte en revanche peu d'attention au rapport avec l'édifice préexistant. De fait, si cette réalisation occupe une place de choix dans les manuels d'architecture, elle mérite aussi d'apparaître dans une " histoire de la transformation des édifices », posture défendue par Roberto Pane dans sa contribution, «L'antico e le preesistenze tra Umanesimo e Rinascimento», à I'ouvrage collectif Verso una storia del restauro (Casiello, 2008). L'article décrit les conditions économiques, sociales, politiques et culturelles du projet, discute du rapport aux préexistences explicité dans les écrits d'Alberti, mais la relation entre neuf et ancien ne fait pas l'objet d'une attention poussée.

On se concentrera donc ici sur la nature de la relation établie entre l'église existante et les façades d'Alberti pour essayer de compléter ainsi les études portant sur cet édifice qui ont été publiées.

\section{Aperçu historique}

En 1447, Sigismond Malatesta, souverain de Rimini, exprime le souhait de transformer l'église de Saint-François (XIIe siècle) en un mausolée réservé à sa propre famille, les Malatesta, ainsi qu'aux hommes «illustres» de sa cour. II confie cette mission à Leon-Battista Alberti, dont l'œuvre sera interrompue suite aux guerres locales (ayant 
(V) Ilustration 5. Plans de la transformation du temple malatestien

Source : dessins de l'auteur d'après Franco Borsi (1980). éloigné le commanditaire de ce projet), suivies de la mort de Sigismond, laissant la façade principale ainsi que celle du chœur, inachevées.

Avant l'intervention d'Alberti, l'église San Francesco à Rimini se présente sous la forme d'un édifice de plan rectangulaire simple, construit en brique et revêtu en façade par un enduit. Elle compte une nef simple, bordée de part et d'autre par quatre chapelles. Le rythme que créent à l'intérieur de l'église les proportions de ces chapelles, leur degré d'ouverture sur la nef, ainsi que les baies qui les éclairent, se retrouve également en façade dans l'espacement entre les baies. Deux types de chapelles s'alternent dans la composition : des chapelles (A) largement ouvertes sur la nef et possédant deux baies en façade; des chapelles (B) ouvrant sur la nef par une porte étroite et en façade par l'intermédiaire d'une seule baie. Les chapelles sont disposées selon un rythme AABAAAA. De manière générale, l'édifice est peu ouvert en façade et dépourvu de décorations et ornements.

\section{Analyse}

Le premier élément important à noter est que la modification n'a pas comporté de démolitions, car Alberti s'est volontairement limité à ajouter de la matière pour créer la nouvelle façade extérieure de l'édifice. Il décrit ainsi sa propre intervention : «talvolta si addossa una parete a un'altra come una pelliccia infilata sopra un vestito» ${ }^{10}$ (Alberti, éd. 1966, p. 325). Pour cela il a enveloppé l'édifice existant dans trois nouvelles façades dessinées selon les

10 Parfois une paroi est adossée à une autre, comme une fourrure que I'on enfile sur un vêtement. règles d'une composition architecturale largement référencée à I'antiquité. Les nouvelles façades voilent presque entièrement les façades préexistantes, qui sont laissées intactes. (Illustration 5)

\section{Temporalité, attitude architecturale, référence à l'ancien}

Réalisée deux cents ans après la construction de l'église de Saint-François, la transformation d'Alberti illustre clairement la rupture intellectuelle et historique qu'a entraîné la redécouverte de l'art antique, dont l'architecte a été l'un des principaux porte-voix. Le style (forme, vocabulaire architectural et décor) de l'édifice s'inspire de l'Antiquité, sans qu'aucun lien ne soit établi entre l'édifice ancien et les éléments ajoutés. La référence à l'antique est poussée jusque dans les détails, car certains matériaux de la façade principale ont été récupérés sur des édifices romains.

\section{Composition dans la confrontation}

Le projet d'Alberti propose une mise en contraste entre neuf et ancien par le biais du contraste, à la fois dans les matériaux, le rythme, la structure, le décor et la géométrie.

Sur les façades latérales, le rythme des nouvelles arcades (CCCCCCC), est indépendant de celui des fenêtres de l'église existante (AABAAAA) et il correspond à son propre système de mesure en référence aux " arcs intérieurs du Colisée » (Pane, 2008, p.96) qu'Alberti a scrupuleusement relevés. Ce dernier reproduit le même nombre de baies, mais il en propose une nouvelle interprétation. Les sept arcades créent un rythme régulier qui entraîne un décalage entre les
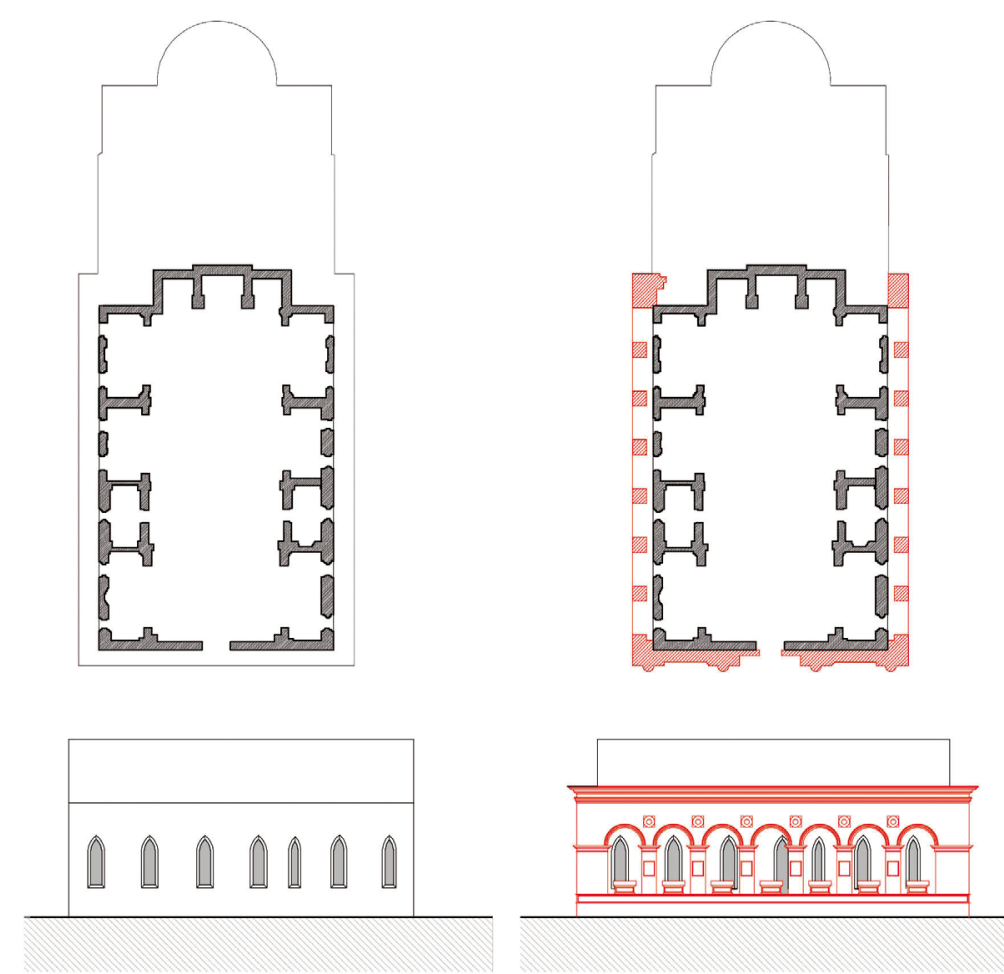
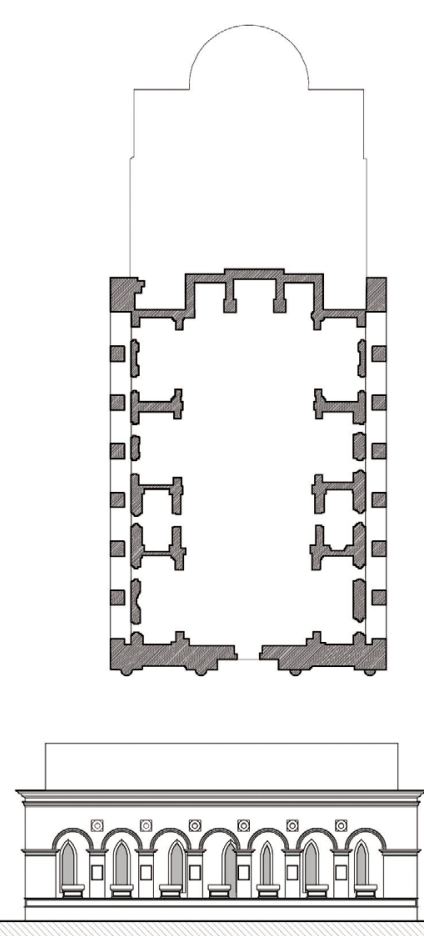

Om 
nouvelles et les anciennes ouvertures, donnant ainsi la sensation que le rythme de l'ancienne façade était aléatoire et chaotique, à l'exact opposé de la rigueur du rythme introduit par Alberti. (Illustration 6)

Les ouvertures existantes sont hautes et étroites, tandis que celles qui ont été ajoutées sont presque aussi larges que hautes. Les baies existantes sont couronnées par des ogives, celles d'Alberti par des arcs en plein cintre. De ce fait, les discordances se manifestent également au niveau des appuis des linteaux des baies, qui sont décalés. Tous les éléments d'architecture nouvellement projetés entrent en contraste avec ceux qui existaient précédemment.

La façade principale, couronnée par une grande arcade, est plaquée contre l'ancienne, dont elle laisse voir le faîtage. On ignore toutefois s'il s'agit là d'un parti adopté par l'architecte ou simplement le résultat du fait que les travaux ont été interrompus avant d'avoir été terminés. En revanche, on lit dans cette juxtaposition la volonté de rendre la nouvelle façade indépendante, sans lien avec la composition intérieure de l'édifice préexistant. Comme pour les façades latérales, la nouvelle façade se réfère entièrement à l'antique comme le démontre Franco Borsi (1980). Pour sa part, Andrea Pane souligne que la relation établie par Alberti avec l'existant se fait «sans se préoccuper d'un quelconque alignement avec les ouvertures gothiques existantes» (Casiello, 2008, p. 96).

Les nouvelles façades dessinées par Alberti sont plaquées sur trois côtés de l'édifice médiéval ; le quatrième côté aurait normalement dû subir le même traitement. Cet « habillage » donne à voir partiellement l'ancienne façade dans le vide laissé par les arcades. Bruno Zevi affirme que la non correspondance entre les baies existantes et celles ajoutées « est pour lui signe de probité et de respect » (Zevi, 1983, p. 38). On pourrait cependant y voir aussi une forme de contestation qui mettrait une distance entre une architecture existante peu considérée et les nouveaux critères de beauté inspirés des modèles antiques.

\section{Matériaux, structure}

Dans le choix des matériaux employés pour réaliser l'intervention, une nouvelle forme d'antagonisme s'ajoute aux précédentes. L'église médiévale est bâtie en brique et revêtue d'un enduit. Les baies gothiques de la façade existante sont en pierre et présentent les seuls éléments de décor des façades. L'intervention d'Alberti est intégralement mise en œuvre en pierre blanche.

Du point de vue de la structure, « il se détache des structures plus anciennes, réalisant une enveloppe constituée d'une séquence d'arcs portés par des piliers massifs »(Pane, 2008, p. 96). Les nouvelles façades, fondées en retrait par rapport aux anciennes, n'entravent donc pas leur

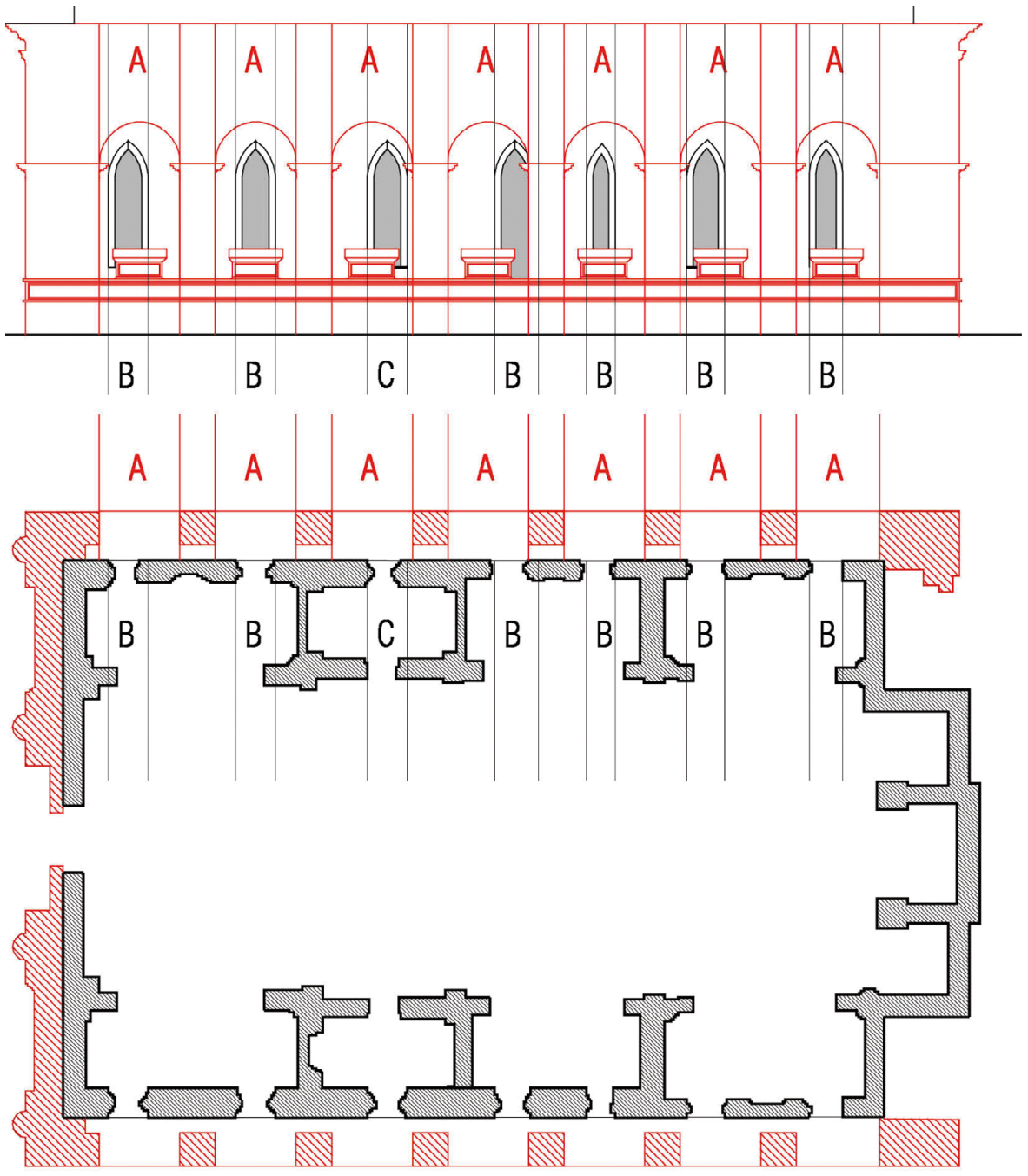

équilibre structurel existant et cela rend l'intervention théoriquement réversible.

\section{Rapport au passé}

Le contraste établi à divers niveaux entre la façade existante et celle qu'Alberti a ajoutée marque une rupture avec la pensée de la période précédente. La nouvelle enveloppe laisse voir I'ancienne façade en second plan derrière les arcades, mais la lecture de cette façade est faussée. En mettant à distance la façade ancienne et en la faisant sembler chaotique, on peut penser qu'Alberti est convaincu de la supériorité des principes de composition inspirés de l'Antiquité.

\section{Interroger le projet au regard de questionne- ments actuels}

Comme le montre Roberto Pane, Alberti affiche dans ses écrits un respect marqué pour les constructions existantes précisant qu'il « est préférable de laisser intactes les structures antiques tant que les nouvelles peuvent être érigées sans démolir ${ }^{11} \gg$ (Alberti, ed. 1966, p.442). Aucune démolition n'a été effectuée, ni en élévation, ni même au niveau des fondations, qui n'ont pas été touchées.

11 « è préferibile lasciar intatte le antichecostruzioni fintanto che le nuove possano essere innalzate senza demolire »
A Illustration 6. Rencontre du rythme existant et du nouveau rythme des ouvertures en façade Source : dessins de l'auteur d'après Franco Borsi (1980). 
Les nouvelles façades s'adossant aux anciennes, elles pourraient être déposées en dévoilant un état antérieur intact. C'est dans cette volonté de ne rien démolir qu'on entrevoit le respect d'Alberti pour les préexistences et que se révèle une posture architecturale forte, celle de la conservation et de la stratification. Cette position rejoint celle des partisans actuels de l'intervention minimale et du respect de l'existant.

Le projet d'Alberti renvoie à d'autres préoccupations présentes, à travers la mise en contraste du neuf et de l'ancien, et par le choix de solutions qui anticipent les prescriptions de la Charte de Venise concernant la lisibilité et la réversibilité des interventions. Par les dispositifs mis en place dans ce projet, l'intervention est de fait tout aussi lisible que réversible. L'emploi de matériaux différents permet de distinguer nettement les deux états et ainsi de respecter le principe de vérité historique, car l'intervention« ne falsifie pas le document d'art et d'histoire» et en conserve le statut de « document » (Charte de Venise, 1964, p. 2).

Toutefois si son œuvre paraît préfigurer certaines interventions contemporaines, elle en diffère en ce que le projet d'Alberti visait à donner à l'édifice une nouvelle image et une nouvelle façade, contrairement à la plupart des projets actuels qui mettent plutôt en valeur l'ancien en conservant les façades extérieures pour restructurer complètement l'intérieur. C'est notamment ce que proposent Herzog et de Meuron à la Tate Modern de Londres ou à la Caixa de Madrid lorsqu'ils mettent en avant les façades anciennes en y ajoutant une touche contemporaine sous forme d'un couronnement lumineux ou en corten. L'attitude d'Alberti peut toutefois être assimilée à celle, relativement exceptionnelle en France, des architectes Lacaton et Vassal à la Tour Bois-le-prêtre à Paris, qui ont proposé une nouvelle enveloppe pour l'édifice dont la structure est simplement juxtaposée à l'ancienne. Ils ont redonné une nouvelle figure à un édifice, des années 1950, peu considéré du point de vue esthétique.

\section{CONCLUSION}

L'exercice d'analyse effectué sur ces deux projets de transformation d'édifices existants permet de faire émerger des pistes réflexions sur les dispositifs architecturaux permettant de lier le neuf à l'ancien. Retracer les diverses étapes du projet et utiliser une charte graphique proposée par Bruno Reichlin à l'Accademia di Architettura di Mendrisio pour l'élaboration du projet dans les édifices existants (Reichlin, 2006) afin de bien différencier les composantes ; cette technique, mise en œuvre ici, permet de comprendre comment le projet s'est fabriqué en relation avec ce qui existait, de retrouver les intentions et les dispositifs mis en place par les architectes, ainsi que l'attitude et les solutions qu'ils ont adoptées.

A partir de cette analyse graphique, on a pu faire émerger des principes de composition spécifiques à chacun des projets étudiés : la géométrie, la trame, le rythme, la structure. Dans le cas de Saint-Denis, la question de la géométrie est centrale et, à Rimini, c'est l'autonomie du rythme des ouvertures et la mise en contraste qui font composition. Toutefois les deux cas présentent des postures radicalement différentes vis-à-vis de l'édifice existant : à Saint-Denis le projet se fait dans la continuité de l'existant alors qu'au temple de Malatesta l'adjonction s'oppose à l'ancien dans une volonté de contraste.

Ces deux exemples semblent indiquer que la démarche adoptée peut porter ses fruits et renouveler à la fois le corpus de références et les thématiques de composition du projet. Par ailleurs, I'ancienneté de ces interventions permet d'avoir un recul historique nécessaire pour juger le caractère de l'intervention, un recul que nous n'avons pas dans le cas des réalisations contemporaines. Ces projets qui précèdent l'apparition de la notion contemporaine de restauration permettent d'observer une autre attitude architecturale dans l'existant.

\section{RÉFÉRENCES}

Alberti, L.-B. (éd. 1966), De Re Aedificartoria, Livre 6, Restauro degli edifici. Milan : Edizioni il Polifilo.

Boito, C. (2000), Conserver ou restaurer : les dilemmes du patrimoine. Besançon : Les Editions de l'Imprimeur.

Borsi, F. (1980). Leon-Battista Alberti opera completa. Milan : Electa editrice.

Brandi, C. (2000). Teoria del restauro. Torino : Piccola Biblioteca Einaudi.

Brankovic, B. (1990). La basilique de Saint-Denis, Les étapes de sa construction. Courbevoie Éditions du Castelet.

Casiello, S. (2008). Verso una storia del restauro. Dall'età classica al primo Ottocento. Florence : Edizioni Alinea.
Charte de Venise (1964) Charte internationale sur la conservation et la restauration des Monuments et des sites. Venise : Icomos. Récupérer de : http://www.icomos.org/charters/venice_f.pdf

Pane, R. (2008), «L'antico e le preesistenze tra Umanesimo e Rinascimento», in Verso una storia del restauro, Florence : Edizioni Alinea.

Reichlin, B. (2006). Testo teorico sul riuso. Texte non publié. Mendrisio.

Rossi, A. (2004). Architettura della città. Rome : Edizioni Città studi.

Summer Mc Knight, C. (1953). L'Abbaye royale de Saint-Denis 130 photographies de Pierre Devinoy. Paris : P. Hartmann.
Summer Mc Knight, C. (1987). The Royal Abbey of Saint Denis from its beginnings to the death of Suger, 475-1151. New Haven Londres : Yale University Press

Viollet-le-Duc, E. (1967, prem. Ed.1800), Dictionnaire Raisonné de l'architecture française du Xle au XVle siècle, article « restauration ». Paris : F. De Nobele

Wyss, M. (sous la direction de) (1996). Atlas historique de Saint-Denis, des origines au XVIII ${ }^{\mathrm{e}}$ siècle. Paris : Édition de la Maison des Sciences de l'Homme.

Zevi, B. (1983), Leon-Battista Alberti « critico-architetto », pretesti di critica architettonica, in ID : Torino. 


\section{EN LENGUA FRANCESA}

\section{BIBLIOGRAFÍA SELECTA: 2000-20 I 5}

\section{Andrés Ávila-Gómez}

Avila-Gómez, A. (2015). Una mirada a las publicaciones en lengua francesa. Bibliografía selecta: 2000-2015. Revista de Arquitectura, I7(I), I0I-103

\section{(c) (1) (9)}

A continuación, se presenta una bibliografía compuesta por algunas de las publicaciones que han iniciado o que han dado continuidad a los principales temas de investigación y de reflexión, tratados durante lo corrido del presente siglo en las escuelas de arquitectura y en las universidades francesas, en las cuales se abordan con especial énfasis temas y problemáticas provenientes de la arquitectura, el urbanismo y el patrimonio. El conjunto de publicaciones escogidas tiene diversos orígenes, entre ellos sobresalen:

- Tesis doctorales publicadas.

- Publicación de actas o memorias de coloquios internacionales.

- Publicaciones producto de investigaciones para exposiciones especializadas.

- Investigaciones en el marco de convenios entre instituciones públicas y privadas.

- Obras colectivas de investigadores especializados.

Las publicaciones son presentadas de acuerdo con las principales temáticas abordadas en este número, teniendo en cuenta aquellas publicaciones del periodo 2000-2015 de editoriales tan importantes como: Editions de La Villette, Presses Universitaires de Lyon, Presses Universitaires de France, Editions du Patrimoine, La Documentation Française, Cité de I'Architecture et du Patrimoine, Picard, Le Moniteur.

Por otro lado, vale la pena señalar que la presente selección incluye publicaciones editadas no solo en Francia, sino también en países como Bélgica (Mardaga, Editions Archives d'Architecture Moderne), Canadá (Centre Canadien d'Architecture) y Suiza (Librairie Droz, Lars Müller Publishers).

Dado que casi la totalidad de las publicaciones escogidas en el marco de este ejercicio no han sido traducidas aún al español, se ha incluido la traducción del título de cada una de ellas.
(HISTORIA, TEORÍA, CRÍTICA)

Amaldi, P. (2012). Architecture, profondeur, mouvement. Gollion : Infolio Editions.

(Arquitectura, profundidad, movimiento)

Barrier, J. (2005). Les architectes européens à Rome, 17401765. La naissance du goût à la grecque. Paris : Editions du Patrimoine

(Arquitectos europeos en Roma 1740-1765. El nacimiento del gusto por lo griego)

Baudez, B. (2013). Architecture et tradition académique. Rennes : Presses Universitaires de Rennes.

(Arquitectura y tradición académica)

Bercé, F. (2013). Viollet-le-Duc. Paris : Editions du Patrimoine

(Viollet-le-Duc)

Bruant, C., Markovics, A., \& Simonnot, N. (2012). Hôtels des postes patrimoniaux de la métropole parisienne. Versailles : ENSA - Versailles.

(Edificios patrimoniales de correos de la metrópolis parisina)

Bouvier, B. (2004). L'édition d'architecture à Paris au XIXe siècle. Les maisons Bance et Morel et la presse architecturale. Genève : Droz.

(La edición de arquitectura en Paris durante el siglo XIX. Las editoriales Bance y Morel, y la prensa arquitectónica)

Cabestan, J-F. (2004). La conquête du plain-pied. L'immeuble à Paris au XVIIle siècle. Paris : Picard.

(La conquista de la planta baja: El inmueble en París durante el siglo XVIII)

Cabestan, J-F., Lempereur, H. (dir.) (2015). La Samaritaine. Paris : Picard

(Grandes almacenes de La Samaritaine)

Carpo, M. (2008). L'architecture à l'âge de l'imprimerie culture orale, culture écrite, livre et reproduction mécanique de l'image dans l'histoire des théories architecturales. Paris : Editions de La Villette.

(La arquitectura en la era de la imprenta. Cultura oral, cultura escrita, libro y reproducción mecánica de la imagen en la historia de las teorías arquitectónicas)

Carvais, R., Guilerme, A., Nègre, V., \& Sakarovitch, J. (dir.) (2010). Edifice \& artifice. Histoires constructives. Paris : Picard.

(Edificio y artificio. Historias constructivas)

Cohen, J.-L. (2011). Architecture en uniforme. Projeter et construire pour la Seconde Guerre mondiale. Paris: Hazan; Montreal : Centre Canadien d'Architecture.

(Arquitectura en uniforme, proyectar y construir en la Segunda Guerra Mundial)

Cohen, J.-L., \& Frank, H. (dir.) (2013) Interférences/Interferenzen. Architecture : Allemagne-France, 1800-2000. Strasbourg : Editions des musées de Strasbourg. (Interferencias. Arquitectura: Alemania - Francia, 1800-2000)

Cohen, J.-L., \& Grossman, V. (dir.) (2014) La modernité, promesse ou menace ? France - 101 bâtiments, 1914-2014. (Catalogue du pavillon français de la Biennale d'architecture de Venise 2014). Paris : Institut Français / Dominique Carré.

(La modernidad: promesa o amenaza? Francia: 101 edificios, 1914-2014 (Catálogo del Pabellón francés en la Bienal de arquitectura de Venecia de 2014))

Cohen, J.-L. (2015). La coupure entre architectes et inteIlectuels, ou les enseignements de l'Italophilie. Liège : Editions Mardaga.

(La ruptura entre arquitectos e intelectuales o las enseñanzas de la italofilia) 

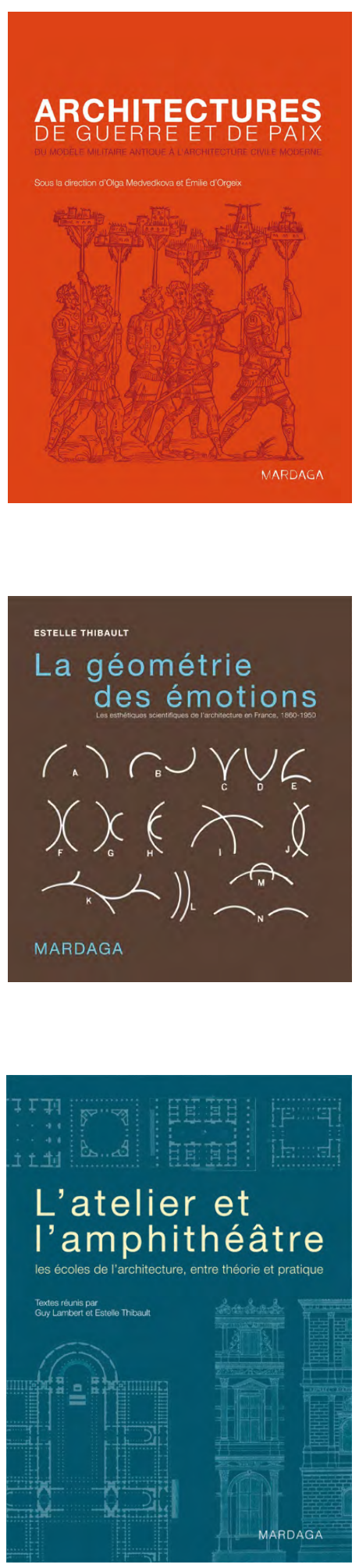

Chabard, P., \& Kourniati, M. (dir.) (2013). Raisons d'écrire. Livres d'architectes, 1945-1999. Paris : Editions de La Villette.

(Razones para escribir. Libros de arquitectos, 1945-1999)

d' Orgeix, E., Garric, J.-P., \& Thibault, E. (dirs.) (2011). Le livre et l'architecte. Wavre : Mardaga. (El libro y el arquitecto)

d'Orgeix, E., \& Medvedkova, O. (2013). Architectures de guerre et de paix. Bruxelles : Mardaga. (Arquitecturas de guerra y de paz)

de Smet, C. (2007). Vers une architecture du livre. Le Corbusier : édition et mise en pages 1912-1965. Zurich : Lars Müller Publishers.

(Hacia una arquitectura del libro. Le Corbusier: edición y puesta en página, 1912-1965)

Deboulet, A., Sauvage, A., \& Hoddé, R. (2008). La critique architecturale. Questions, frontières, desseins. Paris : Editions de La Villette.

(La crítica arquitectónica. Preguntas, fronteras, intenciones)

Didelon, V. (2011). La controverse Learning from Las Vegas. Liège : Mardaga.

(La controversia Learning from Las Vegas)

Eleb, M., \& Simon, P. (2013). Entre confort, désir et normes. Le logement contemporain, 1995-2012. Liège : Editions Mardaga.

(Entre el confort, el deseo y las normas. La vivienda contemporánea, 1995-2012)

Garric, J.-P. (2004). Recueils d'Italie. Les modèles italiens dans les livres d'architecture français. Liège : Mardaga.

(Recopilaciones sobre Italia. Los modelos italianos en los libros franceses de arquitectura)

Garric, J.-P., Nègre, V., \& Thomine-Berrada, A. (dir.) (2008). La construction savante. Les avatars de la littérature technique. Paris : Picard.

(La construcción erudita. Los avatares de la literatura técnica)

Garric, J.-P. (2012). Percier et Fontaine, les architectes de Napoléon. Paris : Belin.

(Percier et Fontaine, los arquitectos de Napoleón)

Garric, J.-P. (2014). Vers une agritecture. Architecture des constructions agricoles (1789-1950). Bruxelles : Mardaga.

(Hacia una agritectura. Arquitectura de construcciones agrícolas, 1789-1950)

Jannière, H. (2002). Politiques éditoriales et architecture «moderne». L'émergence de nouvelles revues en France et en Italie (1923-1939). Paris : Arguments.

(Políticas editoriales y arquitectura "moderna". El surgimiento de nuevas revistas en Francia y en Italia, 1923-1939)

Jannière, H., Sornin, A., \& Vanlaethem, F. (dir.) (2008). Revues d'architecture dans les années 1960 et 1970. Fragments d'une histoire événementielle, intellectuelle et matérielle. Montréal : Institut de recherche en histoire de l'architecture-IRHA.

(Las revistas de arquitectura en los años 1960 y 1970. Fragmentos de una historia evenemencial, intelectual y material)

Jannière, H., \& Leeman, R. (dir.) (2013). Michel Ragon. Critique d'art et d'architecture. Rennes : Presses Universitaires de Rennes.

(Michel Ragon, crítico de arte y de arquitectura)
Lambert, G., \& Thibault, E. (2011). L'atelier et l'amphithéâtre. Les écoles de l'architecture, entre théorie et pratique. Wavre : Mardaga.

(El taller y el aula magna. Las escuelas de la arquitectura, entre teoría y práctica)

Makhneva-Barabanova, O. (2010). Ledoux, maître à penser des architectes russes. Du classicisme au postmodernisme, XVIIIe-XXe siècle. Paris : Editions du Patrimoine.

(Ledoux, maestro de los arquitectos rusos. Del clasicismo al posmodernismo, siglos XVIII-XX)

Mandoul, T. (2008). Entre raison et utopie. L'histoire de l'architecture d'August Choisy. Liège : Mardaga.

(Entre razón y utopía. La Historia de la arquitectura de August Choisy)

Maniaque, C. (2014). Go West. Des architectes au pays de la contre-culture. Marseille : Parenthèses.

(Go West. Los arquitectos en el país de la contracultura)

Mazzoni, C. (dir.) (2014). La Tendenza. Une avant-garde architecturale italienne, 1950-1980. Marseille: Parenthèses.

(La Tendenza: una vanguardia arquitectónica italiana, 1950-1980)

Monnier, G. (dir.) (2006). L'architecture : la réception immédiate et la réception différée. L'oeuvre jugée, l'édifice habité, le monument célébré. Paris : Publications de La Sorbonne.

(Arquitectura: la recepción inmediata y la recepción diferida. La obra juzgada, el edificio habitado, el monumento celebrado)

Morel Journel, G. (2015). Le Corbusier. Construire la vie moderne. Paris : Editions du Patrimoine.

(Le Corbusier. Construir la vida moderna)

Nègre, V. (2006). L'ornement en série. Architecture, terre-cuite et carto n-pierre. Liège : Mardaga.

(El ornamento en serie. Arquitectura, terracota y cartón piedra)

Nivet, S. (2011). Le Corbusier et l'immeuble-villas. Liège : Mardaga.

(Le Corbusier y el inmueble-villa)

Pauwels, Y. (2008). Aux marges de la règle. Essai sur les ordres d'architecture à la Renaissance. Liège : Mardaga.

(En los márgenes de la regla. Ensayo sobre los órdenes arquitectónicos del Renacimiento)

Pérouse de Montclos, J-M. (2011). Architecture : description et vocabulaire méthodique ( $1^{\circ}$ ed. 1972). Paris : Editions du Patrimoine.

(Arquitectura: descripción y vocabulario metódico)

Peyceré, D., \& Wierre, F. (dir.) (2009). Architecture et archives numériques. L'architecture à l'ère numérique : un enjeu de mémoire. Paris : Infolio Editions.

(Arquitectura y archivos digitales. La arquitectura en la era digital, un asunto de memoria)

Picon, A. (2010). Culture numérique et architecture : une introduction. Bâle : Birkhauser.

(Cultura digital y arquitectura: una introducción)

Rabreau, D. (2008). Apollon dans la ville. Essai sur le théâtre et l'urbanisme à l'époque des Lumières. Paris : Editions du Patrimoine.

(Apolo en la ciudad. Ensayo sobre el teatro y el urbanismo en el Siglo de las Luces)

Rouillard, D. (2004). Superarchitecture : le futur de I'architecture, 1950-1970. Paris : Editions de La Villette. (Superarquitectura: el futuro de la arquitectura, 1950-1970) 
Thibault, E. (2010). La géométrie des émotions. Les esthétiques scientifiques de l'architecture en France, 1860-1950. Liège : Mardaga.

(La geometría de las emociones. Estéticas científicas de la arquitectura en Francia, 1860-1950)

Thomine-Berrada, A. (2004). Emile Vaudremer, 18291914. Le rigueur de l'architecture publique. Paris : Picard.

(Emile Vaudremer, 1829-1914. El rigor de la arquitectura pública)

Thomine-Berrada, A. (2012). Baltard, architecte de Paris. Paris : Gallimard / Musée d'Orsay.

(Baltard, arquitecto de París)

\section{URBANISMO Y CIUDAD(ES)}

Backouche, I. (2013). Aménager la ville. Les centres urbains français entre conservation et rénovation (de 1943 à nos jours). Paris : Armand Colin.

(Acondicionar la ciudad. Los centros urbanos franceses, entre conservación y renovación, de 1943 hasta nuestros días)

Bellat, F. (2015). Une ville neuve en URSS : Togliatti. Marseille : Parenthèses.

(Togliatti: una ciudad nueva en la Unión Soviética)

Coquerel, S. (2015). L'étoffe des villes. Trente-sept variations urbaines. Marseille : Parenthèses.

(El tejido de las ciudades. Treinta y siete variaciones urbanas)

Grosjean, B. (2010). Urbanisation sans urbanisme. Une histoire de la "ville diffuse". Liège : Editions Mardaga.

(Urbanización sin urbanismo. Una historia de la "ciudad difusa")

Lancret, N., \& Corine, T-O. (2015). Architectures et villes de l'Asie contemporaine. Héritages et projets. Liège : Editions Mardaga.

(Arquitecturas y ciudades del Asia contemporánea: legados y proyectos)

Le Boudec, B., \& Pinon, P. (2004). Les plans de Paris. Histoire d'une capitale. Paris : Le Passage.

(Los planos de Paris. Historia de una capital)

Maumi, C. (2009). Usonia ou le mythe de la ville-nature américaine. Paris : Editions de La Villette.

(Usonia o el mito de la ciudad-viviente americana)

Merlin, P. (2010). Les grands ensembles. Des discours utopiques aux "quartiers sensibles". Paris : La Documentation Française.

(Los grandes conjuntos habitacionales. De los discursos utópicos a los "barrios sensibles")

Paquot, T. (dir.) (2010). Les faiseurs de villes, 1850-1950. Gollion : Infolio Editions.

(Los hacedores de ciudades, 1850-1950)

Pinon, P. (2002). Atlas du Paris haussmannien. La ville en héritage du Second Empire à nos jours. Paris : Parigramme.

(Atlas del Paris haussmaniano. La ciudad heredada desde el Segundo Imperio hasta nuestros días)

Texier, S. (2010). Paris contemporain. De Haussmann à nos jours, une capitale à l'ère des métropoles. Paris : Parigramme. (rev. y aum., $1^{\circ}$ ed. 2005)

(París contemporánea. De Haussmann hasta nuestros días, una capital en la era de las metrópolis)

\section{PATRIMONIO}

Andrieux, J-Y., Chevallier, F. (2014). Le patrimoine monumental. Sources, objets et représentations. Rennes : Presses Universitaires de Rennes.

(El patrimonio monumental. Fuentes, objetos y representaciones)

Bady, J-P., Leniaud, J-M., Cornu, M., \& Négri, V. (dir.) (2013). 1913 : Genèse d'une loi sur les monuments historiques. Mémoire des grandes lois patrimoniales. Paris : La Documentation Française.

(1913: Génesis de una ley sobre los monumentos históricos. Memoria de las grandes leyes sobre patrimonio)

d'Orgeix, E., \& Casciato, M, (dir.) (2012). Architectures modernes : l'émergence d'un patrimoine. Liège : Editions Mardaga.

(Arquitecturas modernas: el surgimiento de un patrimonio)

Choay, F., \& Sainte-Marie-Gauthier, V. (2013). Haussmann, conservateur de Paris. Paris : Actes Sud.

(Haussmann, conservador de París)

Fiori, R. (2012). L'invention du vieux Paris. Naissance d'une conscience patrimoniale dans la capitale. Wavre : Mardaga.

(La invención del París antiguo. El nacimiento de una conciencia patrimonial en la capital)

Gourbin, P. (dir.) (2008). Les monuments historiques de 1940 à 1959. Administration, architecture, urbanisme. Rennes : Presses Universitaires de Rennes.

(Los monumentos históricos de 1940 a 1959. Administración, arquitectura, urbanismo)

Heinich, N. (2009). La fabrique du patrimoine. "De la cathédrale à la petite cuillère". Paris : Edition de la Maison des Sciences de l'Homme.

(La fábrica del patrimonio. "De la catedral hasta la cucharita")

Liaroutzos, Ch. (dir.) (2015). Que faire avec les ruines? Poétique et politique des vestiges. Rennes : Presses Universitaires de Rennes.

(¿Qué hacer con las ruinas? Poética y política de los vestigios)

Lucas, R. (2012). L'invention de l'écomusée. Genèse du parc d'Armorique. Rennes: Presses Universitaires de Rennes.

(La invención del eco-museo. Génesis del parque de Armórica, 1957-1997)

Poulot, D. (2005). Une histoire des musées de France, XVIII - XX siècle. Paris : La Découverte.

(Una historia de los museos en Francia, siglos XVIII-XX)

Poulot, D. (2006). Une histoire du patrimoine en Occident, XVIII-XXI siècle. Du monument aux valeurs. Paris : Presses Universitaires de France.

(Una historia del patrimonio en Occidente, siglos XVIII-XXI. Del monumento a los valores)

Rouillard, D. (2006). Architectures contemporaines et monuments historiques. Guide des réalisations en France depuis 1980. Paris : Editions Le Moniteur. (Arquitecturas contemporáneas y monumentos históricos. Guía de las realizaciones en Francia desde 1980)
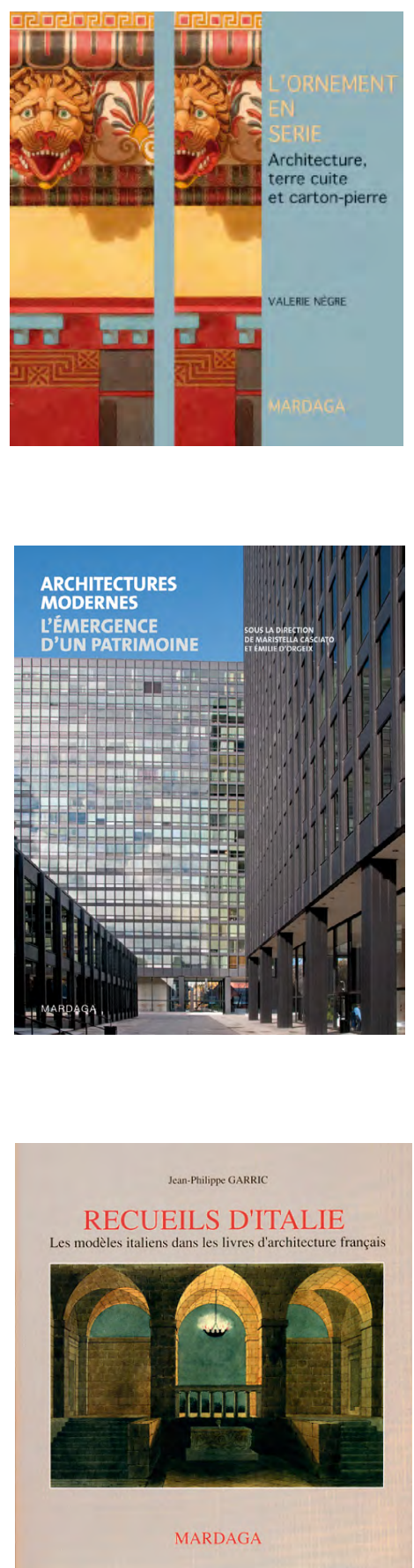

(A) Portada de algunas de las publicaciones

Fuente: Editions

Mardaga (http://www.

editionsmardaga.com/

Architecture-Urbanisme) 


\section{ESTUDIO DE LOS IMAGINARIOS SOCIALES URBANOS DESDE LAS PRÁCTICAS PEDAGÓGICAS}

Fabián Adolfo Aguilera-Martínez, Paula Alejandra Vargas-Niño, Natalia Isabel Serrano-Cruz, María Camila Castellanos-Escobar

Universidad Católica de Colombia. Bogotá (Colombia)

Facultad de Diseño. Centro de investigaciones CIFAR. Semillero de investigación Imaginarios sociales y representaciones

Aguilera-Martínez, F.A., VargasNiño, P.A., Serrano-Cruz, N. \& Castellanos-Escobar, M.C. (2015). Estudio de los imaginarios sociales urbanos desde las prácticas pedagógicas. Revista de Arquitectura, I7(I), 104-II0. doi: 10.14718/RevArq.2015.17.I.10

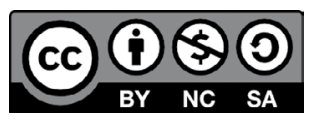

http://dx.doi.org/10.14718/ RevArq.2015.17.1.10
Fabián Adolfo Aguilera-Martínez

Maestro en Proyectos para el Desarrollo Urbano (IBERO), Ciudad de México.

Director del semillero de investigación Imaginarios sociales y representaciones. Universidad Católica de Colombia, Facultad de Diseño.

Docente investigador de distintas facultades de arquitectura en México y Colombia, en temas de urbanismo ambiental sostenible, estrategias de vivienda experimental sustentable y diseño participativo.

(20l4) Caracterización del modelo de aprendizaje a partir de laboratorios de diseño con énfasis en factores sociales. Revista de Arquitectura, 16 (I), 26-37

(2013) Transformación de ciudades deshumanizadas a ciudades Inteligentes. Arka 3, I52-|6|.

(2010) Formulación del proyecto de planificación urbana: Nuevo Centro de Población "Ciudad Esmeralda" México: Secretaría de Planeación y Finanzas del Gobierno del Estado de Tabasco.

urbaguileram@gmail.com

\section{Paula Alejandra Vargas-Niño}

Estudiante de sexto semestre, Facultad de Diseño, Programa de Arquitectura, Universidad Católica de Colombia, Bogotá (Colombia). pavargas04@ucatolica.edu.co

Natalia Isabel Serrano-Cruz

Estudiante de sexto semestre, Facultad de Diseño, Programa de Arquitectura, Universidad Católica de Colombia, Bogotá (Colombia). niserrano64@ucatolica.edu.co

\section{María Camila Castellanos-Escobar}

Estudiante de séptimo semestre, Facultad de Diseño, Programa de Arquitectura, Universidad Católica de Colombia, Bogotá (Colombia). Monitora de investigación del proyecto: Modelo metodológico de diseño para la intervención del hábitat popular urbano; desarrolla instrumentos de verificación y percepción (2015)

milace.91 I@gmail.com

\section{RESUMEN}

El imaginario social es un encuentro de la memoria con la conciencia, una raíz de significados que, por las pérdidas de herencia, olvidamos. El artículo busca mostrar cómo los imaginarios que tienen los estudiantes acerca de su ciudad, se pueden construir desde el aprendizaje a través de la experiencia. El "diseño participativo" es el instrumento en el cual el estudiante, a partir de los grupos de práctica en investigación como formación - "imaginarios sociales y representaciones", construye su imaginario siempre desde lo transdisciplinar; es un encuentro donde los discursos construyen los escenarios pertinentes para actuar a través de las "acciones urbanas"; sin duda, es darle significado a la memoria, pues, de acuerdo con Castoriadis, la creación imaginaria es una consecuencia que nace del ámbito social-histórico que desde la creación de formas culturales se ha convertido para los estudiantes del semillero en "acciones de memoria".

PALABRAS CLAVE: espacio público, enseñanza y formación, identidad colectiva, memoria urbana, representaciones sociales, urbanismo social.

STUDY OF URBAN SOCIAL IMAGINARY FROM PEDAGOGICAL PRACTICES

\section{ABSTRACT}

The social imaginary is a meeting between memory and conscience, a root of meaning that through the losses of heritage, we forget; This article seeks to show how the imaginary students have of their city, can be built through learning from experience. "Participatory design" is the tool through which the student from the practice in research and training group - "social imaginaries and representations", builds his imaginary always from the transdisciplinary; it is a meeting place where discourses create relevant scenarios to act through "urban actions"; it certainly gives meaning to memory because, according to Castoriadis, the imaginary creation is a consequence that comes from a social-historical field which since the creation of cultural forms, has become "Actions of memory" for the students of the undergraduate research group.

KEY WORDS: Public space, teaching and training, collective identity, urban memory, social representations, social urbanism. 


\section{INTRODUCCIÓN}

Este artículo es el resultado del proceso y desarrollo que ha tenido el semillero de investigación Imaginarios sociales y representaciones (ISR), en el cual se han abordado temas tales como el espacio público, el medioambiente y temas culturales de la ciudad. El semillero está conformado por estudiantes ${ }^{1}$ de la Facultad de Diseño, que demuestran interés por reconocer la ciudad y sus escenarios desde los puntos de observación que el arquitecto escenifica como usuario, participando en la construcción urbana en escalas de bajo impacto, que son espacios donde la investigación está contenida a partir de metodologías de participación ciudadana (figura 1).

El semillero Imaginarios sociales y representaciones es una red de discursos y prácticas sociales conformada por una serie de ideales, valores, operaciones y gestos que se relacionan para crear un imaginario claro de ciudad, a partir de un contexto histórico y del supuesto que tienen los habitantes de un lugar determinado; estos imaginarios se crean por un proceso tecnológico fundamentado, no son producto de la casualidad, sino representaciones logradas por códigos, símbolos y signos que hacen parte del lenguaje urbano, la arquitectura y los fenómenos de intervención sobre el contexto; además, las relaciones interpersonales y las normas de la ciudad construyen también significados, como son las percepciones simbólicas y las representaciones basadas en conceptos subjetivos (tabúes, dioses). Este semillero profundiza en la investigación como proceso formativo, con el propósito de generar conocimiento fundamentado de la investigación, desde el campo de la arquitectura por medio de procesos teóricos y de aplicación con intervenciones puntuales en áreas urbanas; asimismo, busca crear mentalidades críticas, con producción de conocimientos de manera constante y con una vocación por la investigación orientada a formar personas integrales y a mejorar la calidad de vidas de las ciudades.

\section{Metodología de LABOR AL INTERIOR DEL SEMILLERO}

El semillero de investigación se ha interesado en la construcción de conocimiento desde la capacidad del estudiante, su visión crítica y bajo una metodología que, fuera de las aulas, pueda ser alternativa de aprendizaje basado en proble-

1 Agradecimiento a las estudiantes y egresadas del semillero de investigación Imaginarios sociales y representaciones de la Facultad de Diseño de la Universidad Católica de Colombia (2015): Luisa Fernanda Celis, Angélica Matallana Quintero, María Camila Castellanos Escobar y a las arquitectas egresadas Laura Viviana González Carrillo y Juliana Murcia, quienes con su dedicación y profesionalismo han sido partícipes de la construcción del trabajo en comunidad.

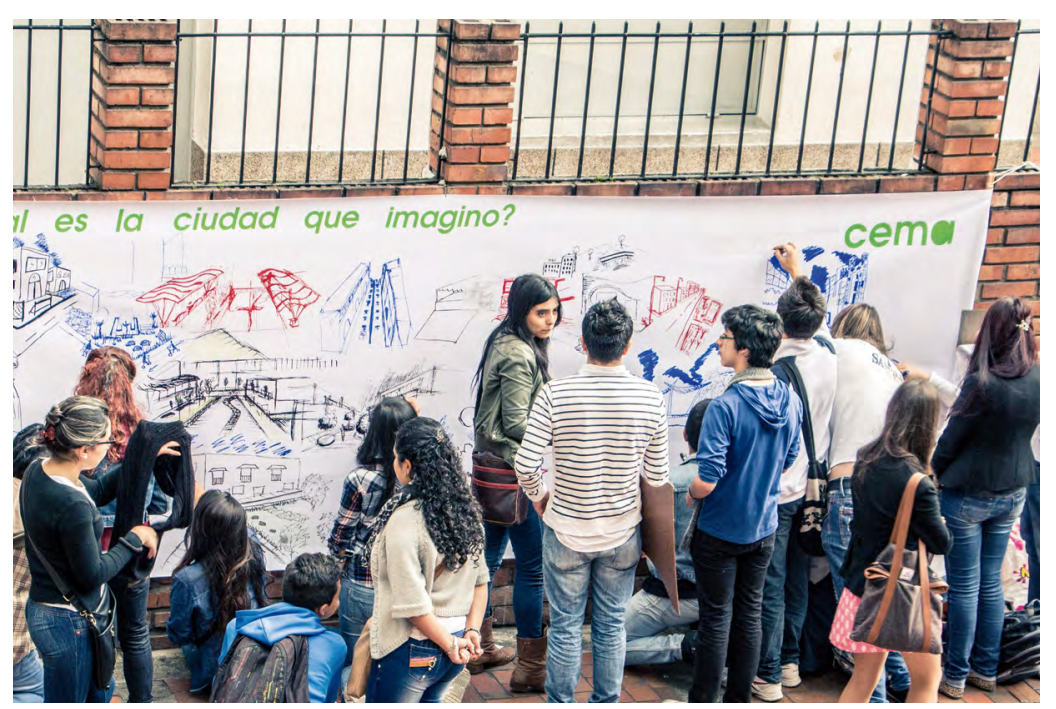

mas, como lo orienta el proceso de aprendizaje del Proyecto Educativo del Programa (Facultad de Arquitectura, 2010).

Las estrategias de motivación han sido fundamentales, entendiendo que la preparación del estudiante debe orientarse a su formación como "joven investigador" 2 y bajo un discurso profesional reflexivo hacia un campo de conocimiento de su disciplina. La utilización de herramientas como el trabajo en cartografía social, la vinculación en procesos de diseño participativo y el desarrollo de derivas de sonido, voz y marcación sensorial, se convierten en instrumentos que los estudiantes toman, incluso, para su trabajo de labor en la academia. Esto permite una articulación del semillero con su modelo de aprendizaje desde lo disciplinar, aprovechando el trabajo fuera de las aulas como incentivo para conocer su mundo: "el lugar en el que actúa".

Es importante reflexionar sobre el trabajo del semillero como parte de una "identidad colectiva", un estado común consciente, que comparten en su comunidad de manera tal, que desde la pertenencia a su entorno, hace que la comunidad los acoja a partir de sus "acciones urbanas"3; al final, esto desencadena una red de intereses que permite que la apropiación sobre el lugar posibilite la construcción de un imaginario ideal (figura 2).

2 El joven investigador es una figura creada por Colciencias, cuya estrategia es estimular a los profesionales recién egresados de las distintas universidades del país, interesados en desarrollar proyectos de investigación e innovación en las diferentes áreas del conocimiento y que deseen contribuir al fortalecimiento y consolidación de los grupos de investigación y a la conformación de una masa crítica de investigadores académicos dentro de la ciencia y la tecnología.

3 Acciones urbanas: ejercicios que funcionan como "acupuntura urbana", los cuales activan de manera apropiada un espacio que ha sido intervenido de manera simple y sin complejidad; la reactivación del lugar y su nueva posibilidad de significación permite que un nuevo "imaginario" se reproduzca a partir de las sensaciones. Muchas veces los parámetros de diseño de las actividades son el juego, la inmaterialidad y lo ficticio.
A Figura 1. Taller con estudiantes alrededor del tema: Percepción de ciudad

Fuente: Archivo semillero de investigación - Foto: Jeanpierre Contreras. 


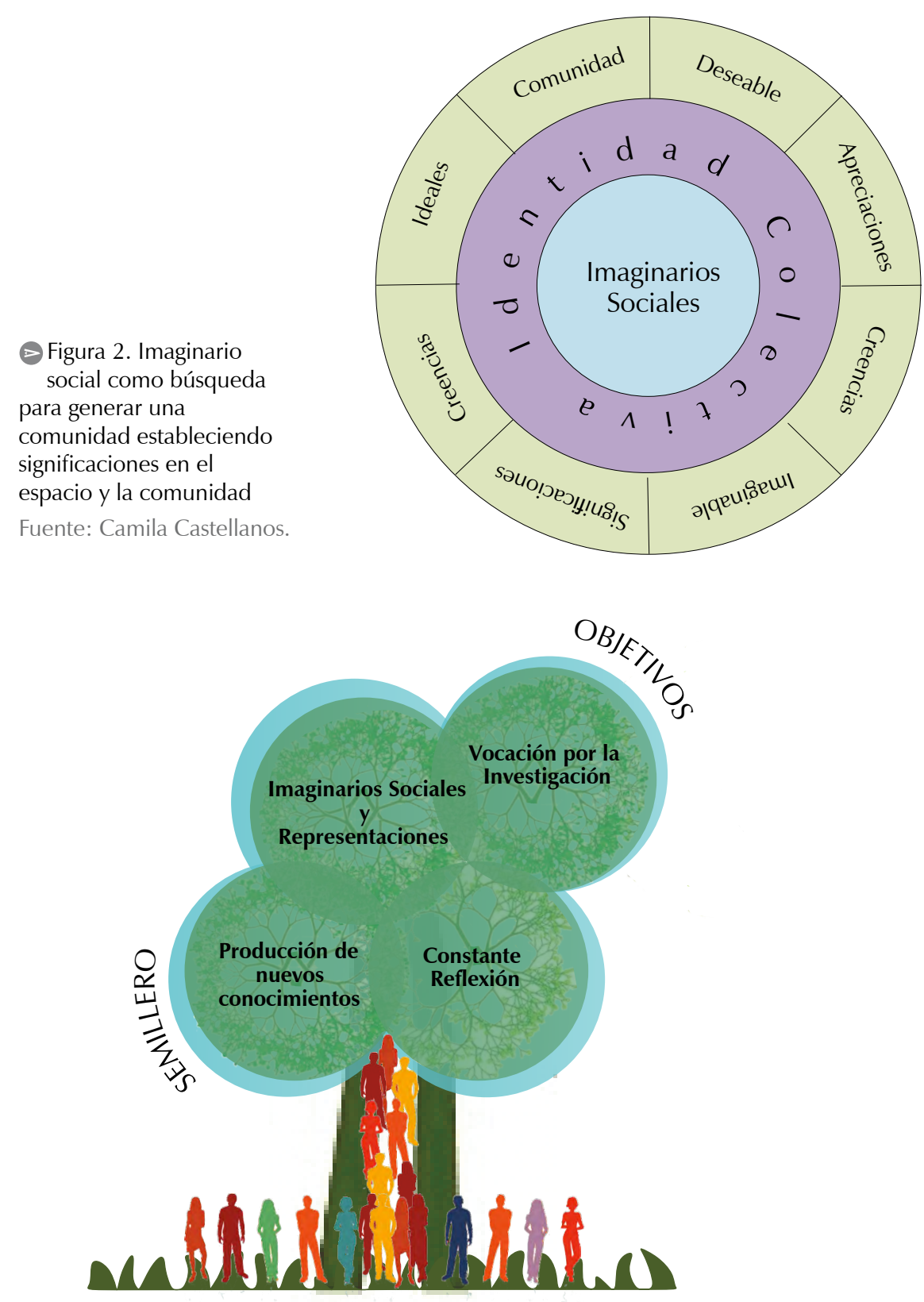

(A) Figura 3. El semillero como vocación por la investigación en la arquitectura

Fuente: Laura V. González.

\section{RESULTADOS}

\section{EL APRENDIZAJE DE LA ARQUITECTURA DESDE LOS SEMILLEROS DE INVESTIGACIÓN}

El semillero de investigación ha sido un escenario de participación colectiva, donde la comunidad hace parte y estructura la cadena de actividades y se convierte en el usuario de cada ejercicio realizado (figura 3). Todas las "acciones urbanas" como resultados y experiencias que, junto a los procesos colectivos, se han obtenido con estudiantes; la indagación y la búsqueda de información desde la rÉcolección de datos, y la investigación como herramienta, permiten la reflexión sobre problemáticas, tratando de dar soluciones por medio de experimentaciones en busca del concepto y de la apropiación (Bolaños y Aguilera, 2014).

El semillero como grupo de trabajo, se encarga principalmente de integrar las necesidades, la cultura y las capacidades de una sociedad en particular, por medio del diseño participativo como metodología que considera los conocimientos, las experiencias presentes y las ideas que se generan en el entorno; su finalidad es adaptarse a un contexto, tomando decisiones que permitan a la comunidad poseer una vivencia con sentido (figura 4). Trabajar con esta metodología lleva implícita la responsabilidad constante de estar integrado a la comunidad, permitiendo la construcción de diferentes cartografías sociales y trabajos sociológicos, en la búsqueda de conocer el habitante con el cual trabajamos, siendo la organización del grupo interventor el medio para realizar este tipo de acciones de manera asertiva.

Por medio del diseño participativo se llevan a cabo una serie de estrategias sistemáticas, conceptuales y acciones que generan diferentes métodos, técnicas y herramientas, para lograr un cambio concreto u objetivo; por medio de estos instrumentos se crean estrategias con recursos adaptables para desarrollar la metodología teórica y metodología de intervención (Mefalopulos y Kamlongera, 2008). También, se generan razones de conciencia sobre los fenómenos y problemas del entorno, desde el conocimiento del imaginario social hacia la ciudadanía, utilizando los marcos contextuales de la investigación; así, por medio del concepto de imaginario social, en el proceso de desarrollo y aplicación del problema, se genera en la ciudadanía un cambio social y cultural, enfatizando en la cultura de la identidad del sector, y se fortalece la memoria y la apropiación que los habitantes deben poseer para poder producir un cambio de mentalidad acerca del espacio urbano.

El objetivo transversal es adquirir el conocimiento apropiado, proveniente del comportamiento de la sociedad, desde el aporte de la investigación como herramienta utilizando mecanismos alternativos como la sensibilización en los procesos de apropiación y pertenencia del espacio urbano. La idea de imaginario articula apropiación, memoria e identidad, a partir de las diferentes percepciones que posee cada habitante en un lugar determinado; cada una de estas representaciones e ideas proporciona un concepto de imaginario colectivo. Esta serie de representaciones es necesaria para el desarrollo funcional de una sociedad; se deben tener en cuenta las cualidades, los defectos, las debilidades y fortalezas que posee un lugar $y$ que generan posiciones que impulsan al habitante a crear un imaginario social, el cual lleva a que cada persona posea un significado y un lenguaje diferente en cada lugar. Estos imaginarios se clasifican dependiendo de la memoria, la morfología, las actividades que se realizan de manera constante, las interacciones sociales y demás acciones que se lleven a cabo en un lugar determinado. Por medio del imaginario social se generan ideales y las conductas de las personas conforman la cultura y la imagen de un sector (Díaz, 1996). 

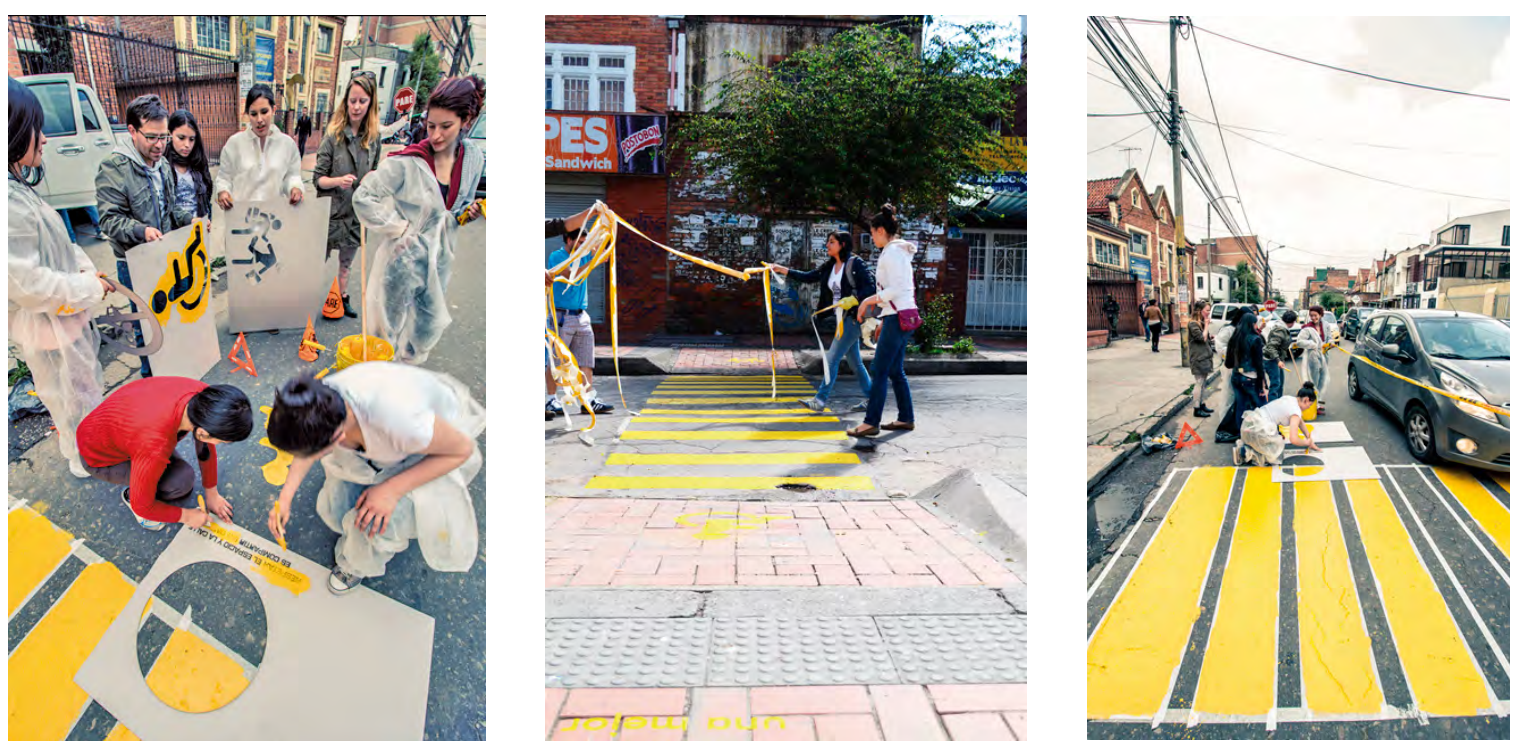

(4igura 4. Acciones urbanas de impacto y reactivación del espacio Fuente: Archivo semillero de investigación - Foto: Jeanpierre Contreras.
El semillero ha logrado fomentar en los estudiantes la vocación por la investigación en arquitectura, urbanismo y medio de producción de nuevos conocimientos para su formación disciplinar; también, encamina a los estudiantes a una reflexión constante sobre las formas y los espacios en los que se manifiesta la vida social y el lugar en el que habitan, instituyendo una manera de pensar basada en la experimentación y la creación de criterios que permiten abrir caminos de entendimiento. De esta manera, el semillero se encarga de brindarle a la sociedad un cambio cultural, para que pueda realizar sus actividades en escenarios habitables y confortables para el desarrollo de sus actividades del diario vivir, en ambientes propicios. Para poder desarrollar y aplicar estos conceptos, es necesario tener una iniciativa propia y conjunta, esto se da por medio del emprendimiento social, escenario donde las relaciones se producen cuando el individuo es capaz de entender que tiene un grado de responsabilidad y se convierte en actor de "cambio social", según expresa Bargsted (2013), donde la puesta en práctica de ideas se orienta al fin de resolver problemas presentes en la sociedad (figura 5).

Ahora bien, para que el habitante se interese por las acciones que se realicen en los espacios públicos u otros espacios históricos, culturales o de interacción, se deben generar ayudas de liderazgo y emprendimiento que sean foco de apoyo para la creación de alternativas que ayuden a fomentar la cultura y visualizar las habilidades que posee cada habitante para que pueda implementarlas en el diario vivir y demostrarlas en los lugares de la ciudad como acciones de apropiación. Estas acciones que se implementan ayudan a la destreza de la sociedad y a la confianza de que cada lugar en ella es un espacio adecuado para entender, dialogar, criticar y apropiarlo de una manera que aporte al entorno, y, si se da el caso, intervenirlo de manera cultural o urbana realizando actividades
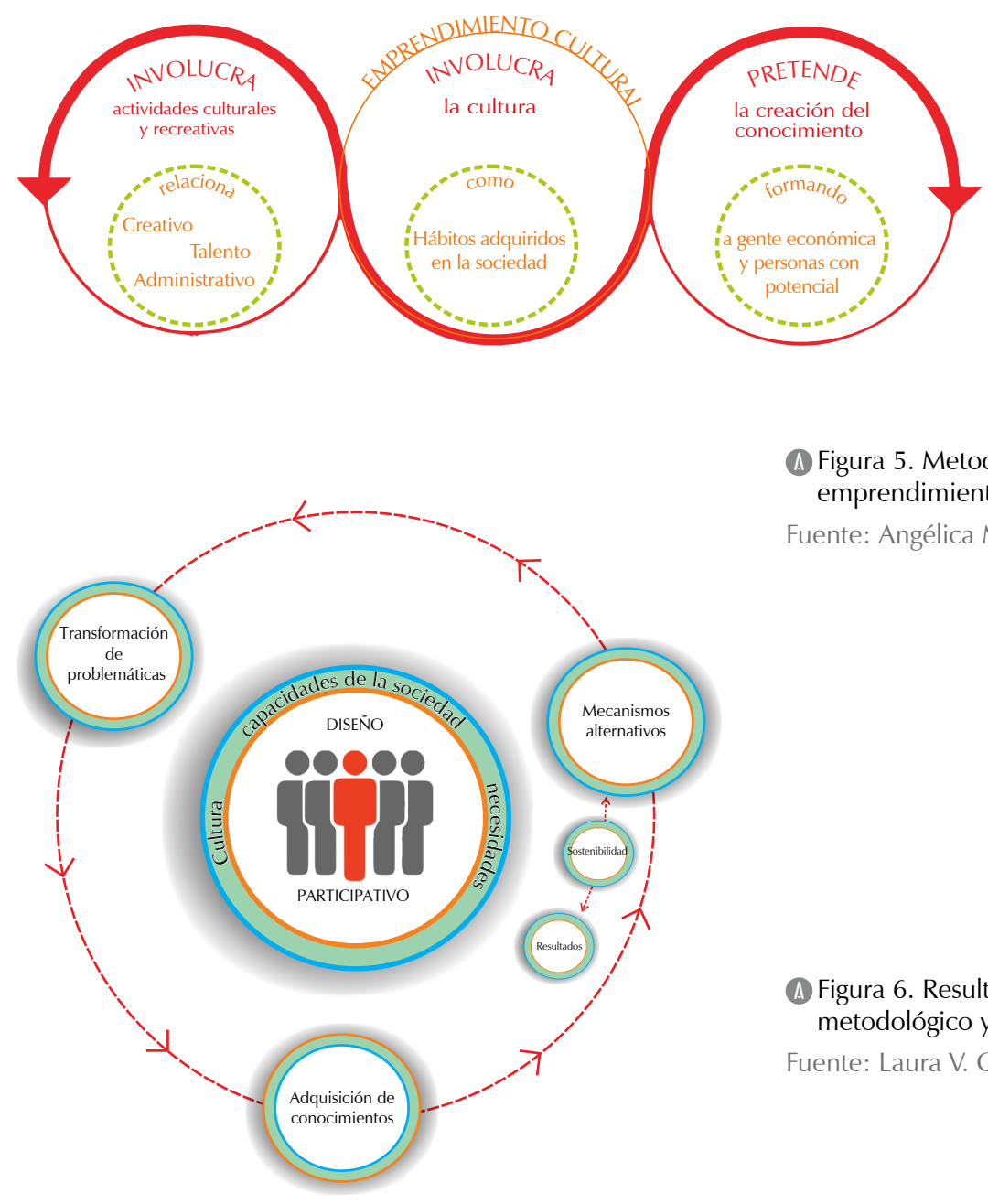

(A) Figura 5. Metodología emprendimiento cultural Fuente: Angélica Matallana.

que ayuden a darle vida, carácter y un lenguaje cuyo objetivo pueda ser entendido por todos los ciudadanos (Steffens, 2013).

Como resultados, se busca que los habitantes entiendan, fomenten y potencialicen la idea de imaginario social como medio de apropiación y de lectura clave para el entendimiento del lugar social, histórico y cultural, con medidas o alternativas que propicien la creación de habilidades y destrezas para el crecimiento de la memoria y el bienestar del lugar (figura 6), por medio de la adquisición de conocimientos a lo largo de la creación metodológica del semillero, a fin de crear 
mecanismos y estrategias diferentes tales como el emprendimiento y el diseño participativo, para generar transformaciones en las problemáticas actuales del territorio, con el objeto de producir cambios de percepciones, emociones e imágenes del sector, potencializando la identidad y la apropiación del lugar (De la Torre Molina, 2008).

\section{DE LAS ACCIONES URBANAS COMO ESCENARIOS}

Lo emergente surge en gran medida de modo autoorganizado como consecuencia de la interacción y colaboración de grupos humanos amplios y diversos, como los que habitan las ciudades. En este sentido, la participación ciudadana surge como motor del proceso, pero entendida no solo como debate y deliberación, sino especialmente como acción directa en la "construcción" de la ciudad (Freire, 2010).

Hablar de "acciones urbanas" es importante, entendiendo el espacio y el escenario como zonas de actuación, donde los habitantes superponen sentimientos de apropiación y pertenencia. Es necesario tener en cuenta, que la participación ciudadana como principal objetivo -identificando las capacidades culturales, las necesidades sociales, mediante la utilización de metodologías de cartografía social—, debe ser un actor determinante para el resultado de la acción (figura 7).

La acción urbana puede ser un complemento interesante del diseño urbano; ejercicio de contemplar, observar y analizar diferentes razones de conciencia a los fenómenos y problemas del entorno desde el conocimiento e imaginario de la ciudadanía, utilizando los marcos contextuales de la investigación que se han desarrollado a lo largo del semillero, al indagar sobre estos pro-
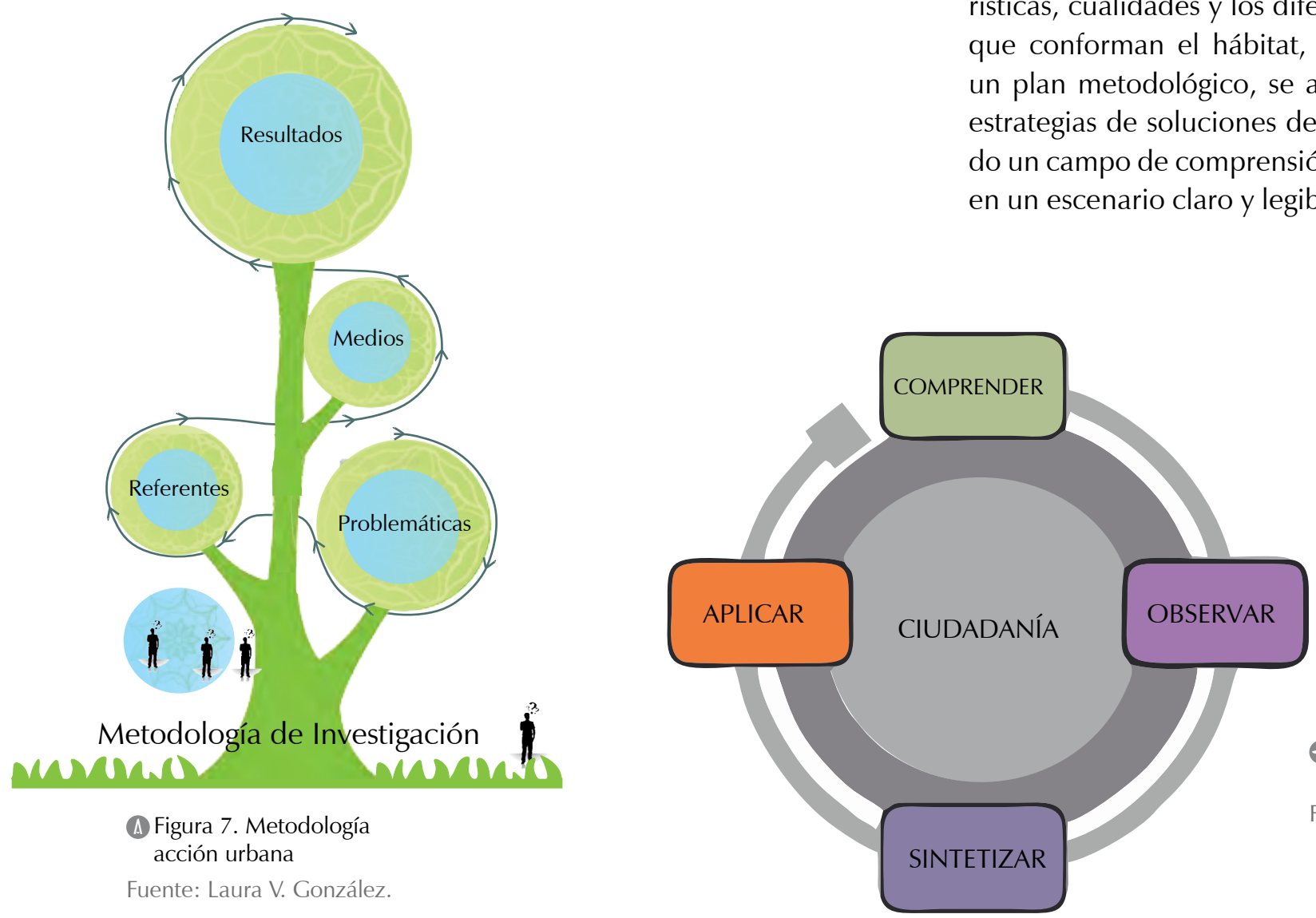

Figura 8. Alcances acción urbana Fuente: Natalia Serrano. blemas de ciudad y de cultura. Por tanto, desarrollar el concepto teórico del semillero aporta a las acciones urbanas hacia la transformación de la ciudad, sin necesidad de grandes gastos económicos, siendo una acción sensitiva y teórica (Aguilera, 2013).

Alcances de las acciones urbanas como estrategia metodológica del semillero (figura 8):

1. Desarrollar de manera abierta proyectos, incentivando la cooperación y la creatividad, permitiendo a las partes establecer una conexión con los resultados obtenidos.

2. Incentivar en la ciudadanía la organización y la toma de decisiones, transformando a ciudadanos comunes y corrientes en actores válidos para el desarrollo de sus barrios.

3. Eliminar barreras que impiden el desarrollo de las capacidades de la comunidad, teniendo a la misma como actor fundamental en la construcción de ciudad.

Por medio de acciones urbanas se construyen nuevos imaginarios que los habitantes crean a partir de los ideales y de la concepción que poseen del lugar. Existen diferentes acciones a través de las cuales los habitantes pueden generar escenarios legibles, vitales y sostenibles; para ello, es necesario crear posibilidades de participación ciudadana, apropiación por medio de la solución de problemáticas sociales, culturales y ambientales. Mediante estrategias legibles para la solución de dichas problemáticas, es necesario crear metodologías que posibiliten a los habitantes aportar a un cambio vital para el sector; así, por medio de la observación, los habitantes crean un imaginario, el cual sintetiza las características, cualidades y los diferentes componentes que conforman el hábitat, por tanto, luego de un plan metodológico, se aplican las diferentes estrategias de soluciones del problema generando un campo de comprensión para los habitantes en un escenario claro y legible para la sociedad y 


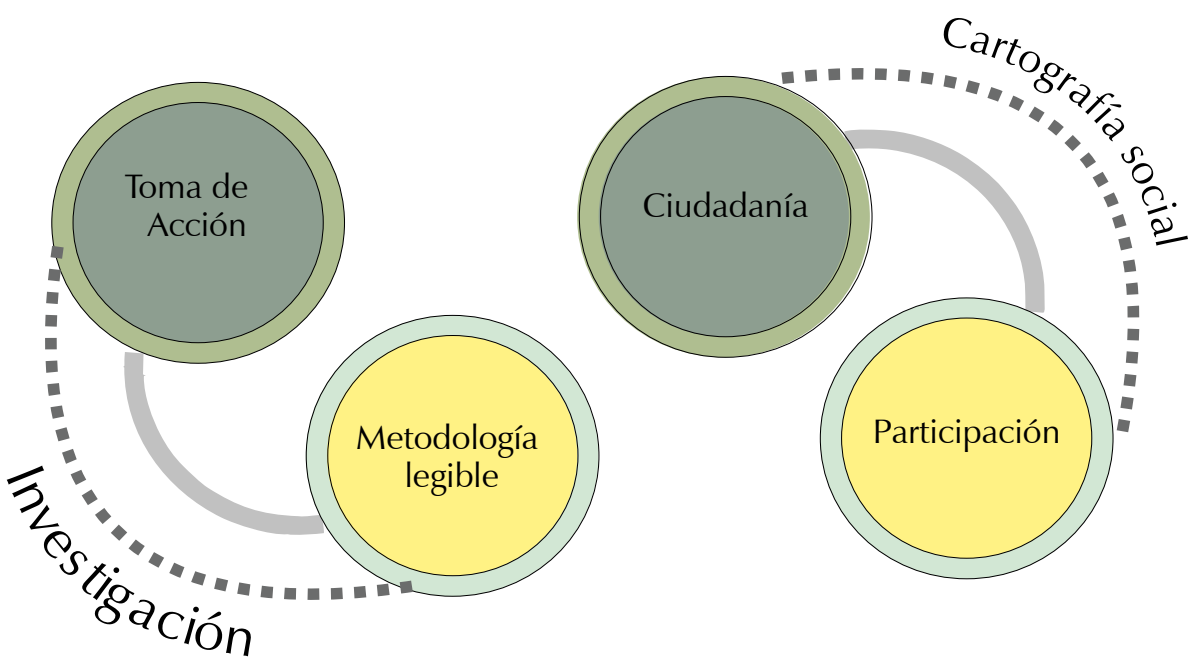

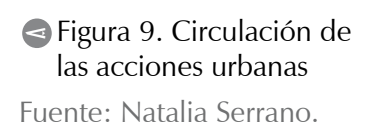

(1) Figura 10. Objetivos acción memoria

Fuente: Angélica Matallana. un punto importante en la ciudad como cambio social y cultural.

La participación que los habitantes aportan al lugar crea un campo de cohesión social el cual elimina cualquier tipo de barreras sociales y culturales, fomentando un lugar de compromiso y de espacios de interacción de la sociedad hacia la ciudad, a partir de la creación de campos de experiencias de sensibilidad y de cambios de percepción hacia la ciudad (Worchel, Cooper, Goethals y Olson, 2002).

Por tanto, por medio de las diferentes experiencias se identifica el lugar como el espacio urbano, y se constituye como herramienta conformadora de las relaciones sociales. Las acciones urbanas y la participación ciudadana, son de vital importancia para la ciudad, dado que configuran elementos que aportan a la estructura del espacio como escenario para el desarrollo de las capacidades humanas y el entendimiento y el desarrollo vital de los habitantes (figura 9).

\section{DE LAS ACCIONES URBANAS COMO MEMORIA}

La memoria colectiva puede ser entendida como el conjunto de conocimientos, valores, reglas y patrones de comportamiento, que adquiridos mediante la interacción entre los miembros del colectivo y su entorno, son compartidos por el grupo con la finalidad de homogeneizar representaciones del pasado y mejorar el resultado de sus decisiones tomando ventajas de las regularidades producidas en el ámbito de su actividad (Hernández, 2005).

Por medio de esta acción, la memoria identifica el carácter positivo de un hábitat; para fortalecer este campo, se utilizan mecanismos alternativos como la sensibilización en los procesos de apropiación y pertenencia en el espacio público, por medio de actividades lúdicas y pedagógicas para el entendimiento claro y efectivo del concepto, categorizando la identidad como un proceso de conformación social-cultural, en busca de la constitución simbólica del espacio, para así elaborar una identidad social, que se constituye a partir del reconocimiento, la
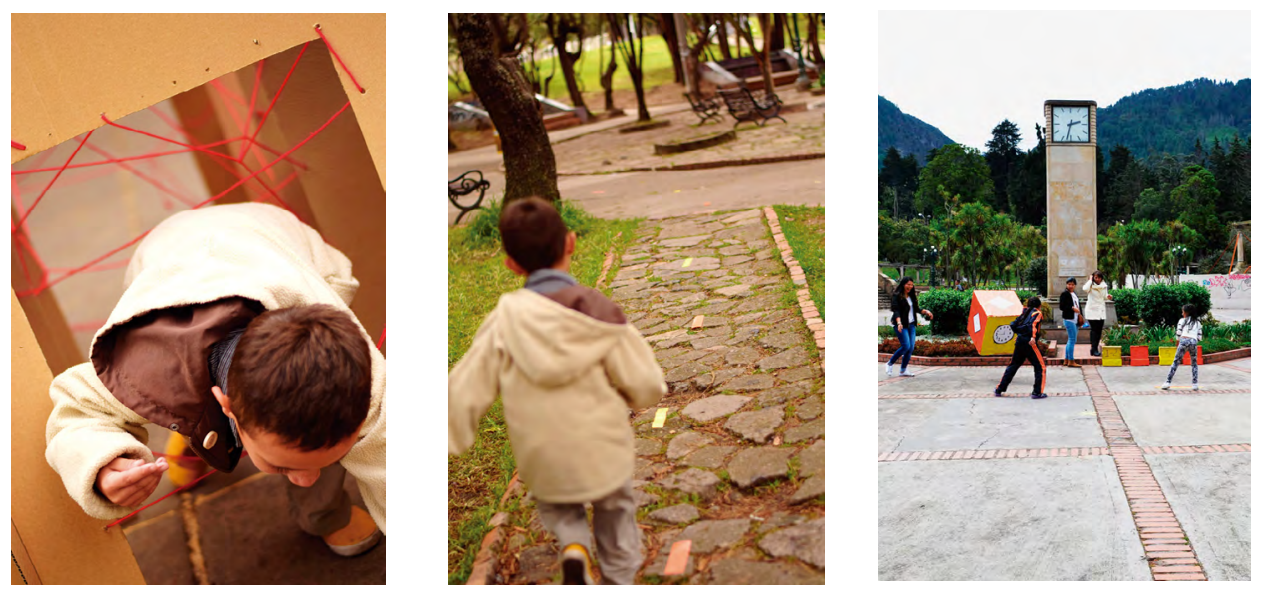

propia identidad y el existencia del otro. Alcances de las acciones de memoria como estrategia metodológica del semillero (figura 10):

1. Categorizar las metodologías apropiadas para el trabajo con la población, en busca de establecer los procesos de construcción de identidad.

2. Plantear la identidad como punto de partida para la construcción de ciudad, entendiendo que la misma no es estática ni coherente.

3. Encaminar una reflexión constante sobre las formas y los espacios en los que se manifiesta la vida social.

Las acciones de memoria, entendidas como un proceso fundamental para la evocación y el carácter que posee la ciudad, generan espacios de reconocimiento de identidad de la urbe. Estos reconocimientos se crean por medio de la apropiación que los habitantes hacen de la ciudad, son la memoria, la identidad y el carácter; estas cualidades fortalecen el recuerdo histórico del lugar; la creatividad aquí juega un papel importante pues
A Figura 11. Acciones de memoria, reconocimiento del lugar (Parque Nacional)

Fuente: Archivo semillero de investigación - Foto: Estudiantes semillero. 
se convierte en herramienta para destacar la innovación como "llamado de atención" para aquel actor que se apropia del lugar (figura 11).

A fin de generar este método de identidad y memoria, la apropiación es un eje fundamental para la identificación de un lugar, el cual se da por medio del conocimiento y el entendimiento del significado que posee un sector; al realizar intervenciones se fortalece la idea de memoria como medio de apropiación (figura 12).

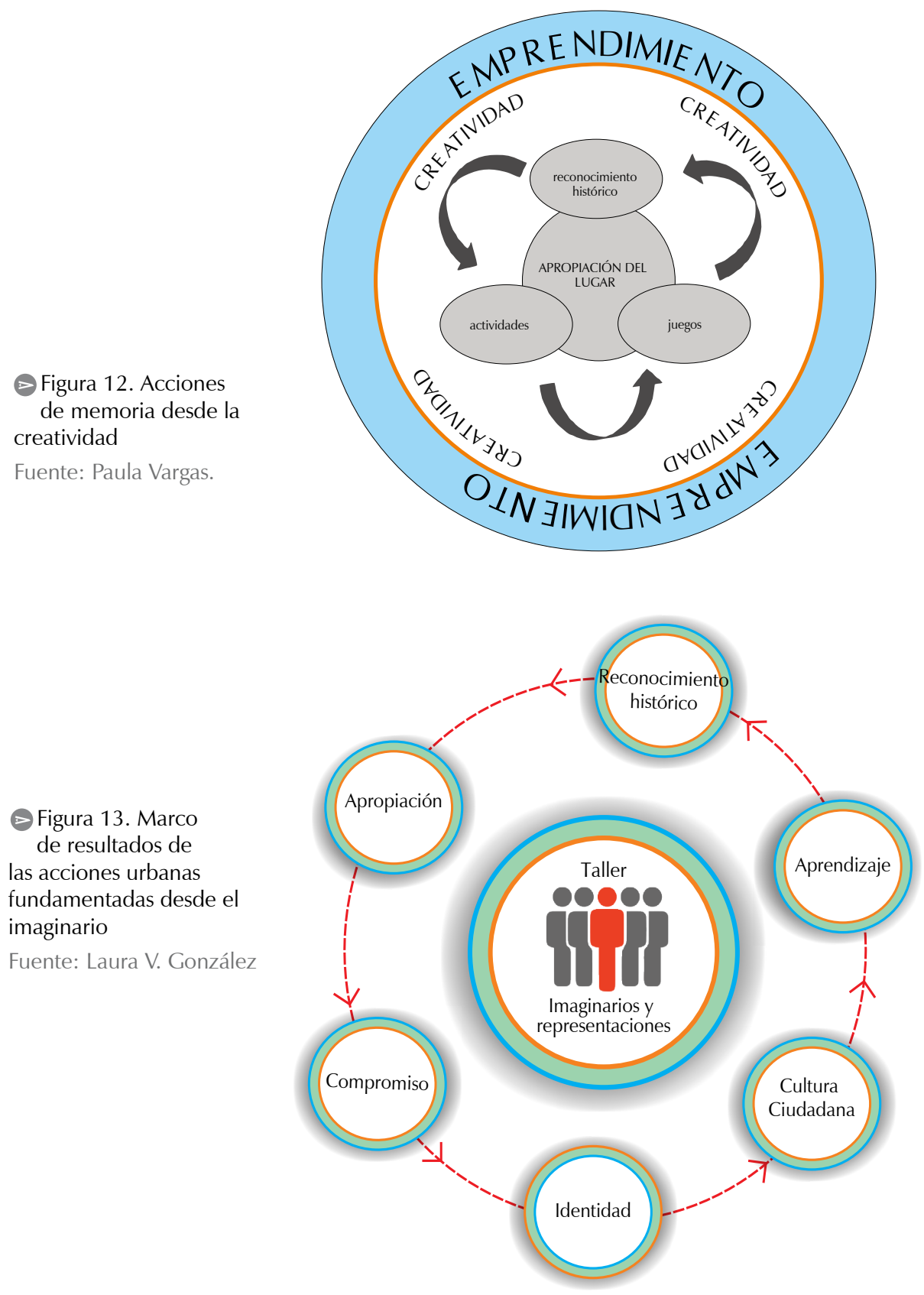

\section{CONCLUSIONES}

La identidad colectiva constituye un elemento vital en la apropiación del espacio; esta abarca las condiciones sociales, culturales y políticas, considerándose dinámica y coherente. Mediante la realización de diferentes acciones, tanto urbanas como sociales y ambientales, se generan campos de apropiación y memoria. Por medio de estas acciones se pudo categorizar cada recuerdo, sensación y percepción, integrando la participación del colectivo en busca de un desarrollo pleno de las capacidades personales. El intervenir y proponer nuevas metodologías en el espacio público, crea un llamado de atención a la arquitectura y la necesidad de abarcar el diseño participativo como parte de la proyección arquitectónica. El semillero Imaginarios sociales y representaciones investiga, genera críticas constructivas, aporta y construye nociones de identidad, apropiación y demás conceptos teóricos que fundamentan el campo urbano de la ciudad. Por medio de las diferentes acciones realizadas, se verifica cómo la utilización del urbanismo táctico — también denominado urbanismo emergente-, incluye a la población como eje central de diseño, concibiendo que es la comunidad quien realiza el mayor uso del lugar y posee las mayores necesidades siendo los actores principales del desarrollo de ciudad (figura 13).

Finalmente, el semillero propicia una reflexión constante en sus participantes, buscando la producción de conocimiento a partir de la experiencia del trabajo en conjunto con la comunidad y la población infantil, generando así campos de producción de conocimiento para ser aplicados a nuevas posibilidades de intervención con la comunidad y los habitantes, a fin de generar escenarios vitales y legibles con identidad y carácter propio.

\section{REFERENCIAS}

Aguilera Martínez, F. (2013). Transformación de ciudades deshumanizadas a ciudades inteligentes. ARKA Revista de Arquitectura, (3), 152-161.

Bargsted, M. (2013). El emprendimiento socia desde una mirada psicosocial. Civilizar. Ciencias Sociales y Humanas, 13 (24), 121-132.

Bolaños Palacios, J. y Aguilera Martínez, F. (2014). Caracterización del modelo de aprendizaje a partir de laboratorios de diseño con énfasis en factores sociales. Revista de Arquitectura, 16, 26-37.

De la Torre Molina, C. (2008). Las identidades: una mirada desde la psicología. La Habana: Instituto Cubano de Investigación Cultural Juan Marinell.
Díaz, E. (1996). La ciencia y el imaginario social. Barcelona: Biblos.

Facultad de Arquitectura (2010). PEP arquitectura. Proyecto educativo del programa (3 ed.). Bogotá: Universidad Católica de Colombia.

Freire, J. (2010). Nómada, blog de juan freire. Sociedad y conocimiento abiertos. Recuperado de http://nomada.blogs.com/ jfreire/2010/03/urbanismo-emergente-ciudad-tecnologa-e-innovacin-social.html

Hernández Ramírez, V. (2005). Reseña de "La memoria colectiva" de Maurice Halbwachs. Athenea Digital. Revista de Pensamiento e Investigación Social, 1 - 7.
Mefalopulos, P. y Kamlongera, C. (2008). Los principios para el diseño de una estrategia de comunicación. En FAO, Diseño participativo para una estrategia de comunicación (pp. 16-24). Roma: División de Comunicación de la FAO.

Steffens, K. (2013). Urbanismo táctico V3: casos latinoamericanos. Recuperado de http:// www.ciudademergente.org/es/publicaciones/urbanismo-tactico-v3-casos-latinoamericanos/

Worchel, S., Cooper, J., Goethals, G. y Olson, J. (2002). Psicología social. Madrid: Paraninfo. 


\section{(A) CON RESPECTO A LOS AUTORES}

Para la Revista de Arquitectura, la postulación de un artículo indica que el o los autores certifican que conocen y aceptan la política editorial, para lo cual firmarán en original y remitirán el formato RevArq FP00 Carta de originalidad.

Para efectos de la autoría y coautoría de artículos se diferencian dos tipos "obra en colaboración" y "obra colectiva". La primera es aquella cuya autoría corresponde a todos los participantes al ser fruto de su trabajo conjunto. En este caso, se requiere el consentimiento de todos ellos para su divulgación. La obra colectiva es en la que, aunque participan diversos colaboradores, hay un autor que toma la iniciativa, la coordinación y realización de dicha obra. En estos casos, la autoría correspondería a dicha persona (salvo pacto en contrario) y sería suficiente únicamente con su autorización de divulgación.

En virtud de mantener el equilibro de las secciones y las mismas oportunidades para todos participantes, un mismo autor puede postular dos o mas artículos de manera simultanea, y previa evaluación de pares, la publicación se hará en volúmenes diferentes.

Se recomienda que el número de autores por artículo no sea superior a cinco integrantes y el orden en que se enuncien corresponda a los aportes de cada uno a la construcción del texto. Si se incluyen más personas se siguiere que sea en calidad de colaboradores o como parte de los agradecimientos. La Revista de Arquitectura respetará el orden en que figuren en el original remitido. La comunicación se establece con uno de los autores, quien a su vez será el responsable de informar a los demás colaboradores.

Una vez publicado el artículo, se envía al autor la versión impresa y digital, las cuales puede distribuir de manera libre respetando la licencia de acceso abierto y la integridad de la Revista de Arquitectura.

Para el caso del autoarchivo, si hay una versión previa (working paper - 'literatura gris' o pre-print) o una versión posterior (revisada o mejorada o post-print), el autor está en libertad de publicarlas en un sitio web o repositorios, siempre haciendo referencia a la publicación realizada en la Revista de Arquitectura.

\section{(A) ACCESO ABIERTO}

La Revista de Arquitectura, en su misión de divulgar la investigación y apoyar el conocimiento y discusión en las campos de interés, proporciona acceso libre, inmediato e irrestricto a su contenido de manera gratuita mediante la distribución de ejemplares impresos y digitales. Los interesados pueden leer, descargar, guardar, copiar y distribuir, imprimir, usar, buscar o referenciar el texto completo de los artículos o la totalidad de la Revista de Arquitectura

Esta revista se acoge una licencia Creative Commons (CC) de Atribución - No comercial - Compartir igual, 4.0 Internacional: "E material creado puede ser distribuido, copiado y exhibido por terceros si se muestra en los créditos. No se puede obtener ningún beneficio comercial y las obras derivadas tienen que estar bajo los mismos términos de licencia que el trabajo original".

(1) (2) Para más información: http://

BY SA Co.creativecommons.org/tipos-de-licencias/

Las licencias CC se basan en el principio de la libertad creativa con fines académicos, científicos, culturales. Las licencias CC complementan el derecho de autor sin oponerse a este.

La Revista de Arquitectura es divulgada en centros y grupos de investigación, en bibliotecas y universidades y en las principales facultades de arquitectura, mediante suscripción anual o canje, este último se formaliza mediante el formato RevArq FP20 Canjes

Para aumentar su visibilidad e impacto de los artículos, se envían a bases de datos y sistemas de indexación y resumen (SIR) y asimismo pueden ser consultados y descargados en la página web de la revista.

\section{$\underset{\text { EDITOLITICA }}{\operatorname{Pa}}$}

APRINCIPIOS ÉTICOS Y BUENAS PRÁCTICAS

La Revista de Arquitectura no tiene tarifa por procesamiento de artículos ni costos asociados al valor de página publicada.

Los artículos publicados en la Revista de Arquitectura son sometidos al cumplimiento de los principios éticos contenidos en las diferentes declaraciones y legislaciones sobre propiedad intelectual y derechos de autor específicos del país donde se realizó la investigación. En consecuencia, los autores de los artículos aceptados para publicar y que presentan resultados de investigaciones, deben firmar la declaración de originalidad, de cesión de derechos y de cumplimiento total de los principios éticos y las legislaciones específicas.

La Revista de Arquitectura se guía por las normas internacionales sobre propiedad intelectual y derechos de autor, y de manera particular el artículo 58 de la Constitución Política de Colombia, la Ley 23 de 1982 y el Acuerdo 172 del 30 de Septiembre de 2010 (Reglamento de propiedad intelectual de la UNIVERSIDAD CATÓLICA DE COLOMBIA).

Los autores, el editor, los miembros de los comités y los pares deben seguir las normas éticas internacionales (http://publicationethics.org) con el fin de evitar casos de fabricación, falsificación, omisión de datos y plagio.

La fabricación de resultados se ocasiona al mostrar datos inventados por los autores; la falsificación resulta cuando los datos son manipulados y cambiados a capricho de los autores; la omisión se origina cuando los autores ocultan deliberadamente un hecho o dato, y el plagio cuando un autor presenta como ideas propias, datos creados por otros. Los casos de plagio son los siguientes: copia directa de un texto sin entrecomillar o citar la fuente, modificación de algunas palabras del texto, paráfrasis y falta de agradecimientos. La revista se apoya en herramientas que detectan cualquiera de estos casos en los artículos postulados.

Una vez constatadas la Revista de Arquitectura podrá hacer públicas las malas prácticas científicas como plagio, falsificación o invención de datos, apropiación individual de autoría colectiva y publicación duplicada por parte del autor o los autores. El autor quedará impedido para postular artículos por dos años.

\section{A MANEJO DE LA INFORMACIÓN Y PRIVACIDAD}

HABEAS DATA

Para dar cumplimiento a lo previsto en el artículo 10 del Decreto 1377 de 2013, reglamentario de la Ley 1581 de 2012 y según el Acuerdo 002 del 4 de septiembre de 2013 de la UNIVERSIDAD CATÓLICA DE COLOMBIA, "por el cual se aprueba el manual de políticas de tratamiento de datos personales"

La UNIVERSIDAD CATÓLICA DE COLOMBIA, considerada como responsable $y / o$ encargada del tratamiento de datos personales, manifiesta que los datos personales de los autores, integrantes de los comités y pares evaluadores, se encuentran incluidos en nuestras bases de datos; por lo anterior y en cumplimiento de las disposiciones legales vigentes, la Universidad solicitará siempre su autorización, para que en desarrollo de sus funciones propias como Institución de Educación Superior, en especial las relacionadas con la docencia, la extensión y la investigación, la UNIVERSIDAD CATÓLICA DE COLOMBIA pueda rÉcolectar, recaudar, almacenar, usar, circular, suprimir, procesar, intercambiar, compilar, dar tratamiento, actualizar, transmitir y/o transferir a terceros países y disponer de los datos que le ha suministrado y que han sido incorporados en las bases de datos de todo tipo que reposan en la Universidad.

La UNIVERSIDAD CATÓLICA DE COLOMBIA queda autorizada, de manera expresa e inequívoca, en los términos señalados por el Decreto 1377 de 2013, para mantener y manejar la información de nuestros colaboradores (autores, integrantes de los diferentes comités y pares evaluadores), así mismo los colaboradores podrán ejercer sus derechos a conocer, actualizar, rectificar y suprimir sus datos personales, para lo cual se han dispuesto las siguientes cuentas de correo electrónico:

contacto@ucatolica.edu.co y revistadearquitectura@ucatolica.edu.co 
La Revista de Arquitectura. recibe de manera permanente artículos y los periodos de publicación son enero-junio y julio-diciembre de cada año. A medida que se van artículos recibiendo artículos se procesan.

El idioma principal es el español y como opcionales están definidos el inglés y el portugués; los textos pueden ser escritos y presentados en cualquiera de estos idiomas.

Los artículos postulados deben corresponder a las categorías universalmente aceptadas como producto de investigación, ser originales e inéditos y sus contenidos responder a criterios de precisión, claridad y brevedad.

Como punto de referencia se pueden tomar las tipologías y definiciones del Índice Bibliográfico Nacional, Publindex, para los artículos tipo 1,2 y 3 que se describen la continuación:

1) Artículo de investigación científica y tecnológica: documento que presenta, de manera detallada, los resultados originales de proyectos terminados de investigación. La estructura generalmente utilizada contiene cuatro apartes importantes: introducción, metodología, resultados y conclusiones.
2) Artículo de reflexión: documento que presenta resultados de investigación terminada desde una perspectiva analítica, interpretativa o crítica del autor, sobre un tema específico, recurriendo fuentes originales.

3) Artículo de revisión: documento resultado de una investigación terminada donde se analizan, sistematizan e integran los resultados de investigaciones publicadas o no publicadas, sobre un campo en ciencia o tecnología, con el fin de dar cuenta de los avances y las tendencias de desarrollo. Se caracteriza por presentar una cuidadosa revisión bibliográfica de por lo menos 50 referencias.

También se pueden presentar otro tipo de documentos diferentes a los anteriormente descritos como pueden ser: artículo corto, reporte de caso, revisión de tema, documento resultado de la revisión crítica de la literatura sobre un tema en particular, cartas al editor, traducción, documento de reflex ión no derivado de investigación, reseña bibliográfica así como proyectos de arquitectura o urbanismo, entre otros.

(A) INSTRUCCIONES PARA POSTULAR ARTÍCULOS

Presentar el artículo mediante comunicación escrita dirigida al Editor de la Revista de Arquitectura (RevArq FP00 Carta de originalidad) ${ }^{1}$, en soporte digital debidamente firmada y una copia impresa (si es local o escaneada), adjuntando hoja de vida del autor (diligenciar el formato RevArq FP01 Hoja de Vida). En la comunicación escrita el autor debe expresar, que conoce y acepta la política editorial de la Revista de Arquitectura, que el artículo no está postulado para publicación simultáneamente en otras revistas u órganos editoriales y que -de ser aceptado- cede todos los derechos de reproducción y distribución del artículo a la UNIVERSIDAD CATÓLICA DE COLOMBIA Como editora de la revista.

Los artículos deben tener en cuenta las siguientes recomendaciones:

- En la primera página del documento se debe incluir

Título: en español e inglés y no exceder 15 palabras.

SUBтítulo: opcional, complementa el título o indica las principales subdivisiones del texto.

DATOS DEL AUTOR O AUTORES: nombres y apellidos completos, filiación institucional (Si el artículo tiene patrocinio, financiación o apoyo de una institución o entidad). Como nota al pie (máximo 150 palabras): formación académica, experiencia profesional e investigativa, vinculación laboral, premios o reconocimientos, publicaciones representativas e información de contacto correo electrónico, dirección postal o numero telefónico.

DESCRIPCIÓN DEL PROYECTO DE INVESTIGACIÓN: en la introducción describir el tipo de artículo y brevemente el marco investigativo del cual es resultado y diligenciar el formato (RevArq FP02 Info Proyectos de Investigación)

RESUMEN:debe ser analítico, se redacta en un solo párrafo, da cuenta del tema, el objetivo, la metodología, los puntos centrales y las conclusiones, no debe exceder las 150 palabras y se presenta en español e inglés (Abstract).

Palabras Clave: cinco palabras o grupo de palabras, ordenadas alfabéticamente y que no se encuentren en el título o subtítulo, deben presentarse en español e inglés (Key words), estas sirven para clasificar temáticamente al artículo. Se recomienda emplear principalmente palabras definidas en el tesauro de la Unesco http://databases.unesco.org thessp/ o en el tesauro de Arte \& Arquitectura (C) www.aatespanol.cl

- La segunda página y siguientes deben tener en cuenta estas recomendaciones:

El cuerpo del artículo generalmente se divide en: Introducción, Metodología, Resultados y Discusión, y finalmente Conclusiones, luego se presentan las Referencias bibliográficas, Tablas, Leyendas de las Figuras y Anexos.

Texтo: Todas las páginas deben venir numeradas y con el título de artículo en la parte inferior (pie de página). Márgenes de $3 \mathrm{~cm}$ por todos los lados, interlineado doble, fuente, Arial o Times New Roman de 12 puntos, texto justificado. La extensión de los artículos debe estar alrededor de 5.000 palabras ( \pm 20 páginas, incluyendo gráficos, tablas, etc.); como mínimo 3.500 y máximo 9.000 palabras. Se debe seguir el estilo vigente y recomendado en el Manual para Publicación de la Asociación Americana de Psicología (APA). (Para mayor información http://www.apastyle.org/).

CitAS Y NOTAS AL PIE: las notas aclaratorias o notas al pie no deben exceder cinco líneas o 40 palabras, de lo contrario estas deben ser incorporadas al texto general. Las citas pueden ser:

Corta (con menos de 40 palabras) se incorporan al texto y pueden ser: textuales (se encierran entre dobles comillas), parafraseo o resumen (se escriben en palabras del autor dentro del texto).

Cita textual extensa (mayor de 40 palabras) debe ser dispuesta en un renglón y un bloque independiente con sangrías y omitiendo las comillas, no olvidar en ningún caso la referencia del autor (Apellido, año, p. 00).

REFERENCIAS: como modelo para la construcción de referencias se emplea el siguiente:
Libro

Autor-Apellidos-, A.A.-Nombres- (año de la publicación). Título de la obra. (Edición). Ciudad, País: Editorial.

Capítulo de un libro

Autor, A.A., \& Autor, B.B. (Año de la publicación). Título del capítulo. En A.A. Editor \& B.B. Editor (eds.), Título del libro (páginas del capítulo). Ciudad: Editorial.

\section{Publicación seriada (Revista)}

Autor, A.A., Autor, B.B., \& Autor, C.C. (Año de la publicación, incluya el mes y día de la publicación para publicaciones diarias, semanales o mensuales). Título del artículo. Título de la revista, diario, semanario, Volumen, (número), páginas.

Leyes, decretos, resoluciones, etc.

Ley, decreto, resolución, etc., número (Año de la publicación, incluya el mes y día de la publicación). Título de la ley, decreto, resolución, etc. Título de la publicación oficialmente. Ciudad, País

Artículo que se encuentra en una revista publicada en Internet Autor, A.A. \& Autor, B.B. (año, si se encuentra). Título del artículo. Título de la revista, volumen, (número). Recuperado de URL.

SiGLAs: en el caso de emplear siglas en el texto, cuadros, gráficos y/o fotografías, se deben proporcionar las equivalencias completas de cada una de ellas la primera vez que se empleen y encerrarlas entre corchetes [ ]. En el caso de citar personajes reconocidos se deben colocar nombres y/o apellidos completos, nunca emplear abreviaturas.

GRÁFICOS Y TABLAS: las figuras (gráficos, diagramas, ilustraciones, planos, mapas o fotografías) y las tablas deben contener número, título o leyenda explicativa relacionada con el tema del artículo que no exceda las 15 palabras (Figura $01 \mathrm{xxxxx}$, Tabla $01 \mathrm{xxxx}$, etc.) y la procedencia (autor $y /$ o fuente, año, p. 00). Estos se deben incluir en el texto y se deben citar de forma directa o entre paréntesis; se recomienda hacerlo mediante referencias cruzadas.

También se deben entregar en medio digital independiente del texto en formatos editables o abiertos. La numeración debe corresponder a la posición en el texto y según la extensión del artículo se deben incluir de 5 a 10 gráficos

El autor es el responsable de adquirir los derechos y/o las autorizaciones de reproducción a que haya lugar, para imágenes y/o gráficos tomados de otras fuentes, así como de entrevistas o material generado por colaboradores diferentes a los autores.

Fotografía: pueden ser entregadas en original para ser digitalizadas, de lo contrario se deben digitalizar con una resolución igual o superior a 300 dpi para imágenes a color y 600 para escala de grises. Los formatos de las imágenes pueden ser TIFF, PSD o JPG y deben cumplir con características expresadas en el punto anterior (gráficos)

Planimetría: se debe entregar la planimetría original en medio digital en lo posible en formato CAD y sus respectivos archivos de plumas o en PDF, de no ser posible se deben hacer impresiones en tamaño carta con las referencias de los espacios mediante numeración y lista adjunta. Deben tener escala gráfica, escala numérica, norte, coordenadas y localización. En lo posible no se deben textos, achurados o tramas.

Para más detalles, consultar el documento RevArq Parámetros para Autores-Descripción, en el portal web de la Revista de Arquitectura.

\section{BENEFICIOS}

Como reconocimiento a los autores, se les hará envío postal de dos (2) ejemplares de la edición impresa sin ningún costo y entregada en la dirección consignada en el formato de hoja de vida (RevArq FP01) adicionalmente se les enviará el vínculo para la descarga de la versión digital. También se enviará una constancia informativa en la que se relaciona la publicación del artículo y de manera opcional se puede detallar las fechas del proceso editorial y el arbitraje realizado. 
La selección de pares evaluadores se realiza de acuerdo con los siguientes criterios:

- Afinidad temática.

- Formación académica.

- Experiencia investigativa y profesional.

- Producción editorial en revistas similares o en libros resultado de investigación.

El proceso de arbitraje se basa en los principios de equidad e imparcialidad y en los criterios de calidad y pertinencia.

El desarrollo de la evaluación se realiza según el formato RevArq FP10 Evaluación de artículos calidad y las observaciones que el par considere necesarias en el cuerpo del artículo. En cualquiera de los conceptos que emita el par (aceptar, aceptar con modificaciones o rechazar) y como parte de la labor formativa y de comunidad académica, el par expondrá sugerencias para mejorar el documento. El par evaluador podrá solicitar una nueva relectura del artículo después de los ajustes realizados por el autor.

El par también deberá diligenciar el formato RevArq FP01 Hoja de Vida, con el fin de certificar y soportar el proceso de evaluación ante los SIR que así lo soliciten.

En el proceso de arbitraje se emplea el método doble ciego, los nombres de evaluador no serán conocidos por el autor y viceversa. Con el fin de garantizar el anonimato del autor, al artículo postulado se le han podido suprimir nombres, instituciones o imágenes que puedan ser asociadas de manera directa al autor.

Aunque se procura el anonimato, una vez recibida la invitación a evaluar el artículo, el par debe cerciorarse de que no exista conflicto de intereses o alguna limitante que afecte la evaluación o que pueda ser vista como tal (lazos familiares, amistad o enemistad, vínculos contractuales o laborales, posiciones éticas, etc.), de presentarse esta situación se notificara al editor.

Dada la confidencialidad del proceso de evaluación y considerando los derechos autor y de propiedad intelectual que pueda haber sobre el material que se entrega, el evaluador se compromete a mantener en absoluta reserva su labor, a limitar el uso de la obra entregada solo para el propósito de evaluación y a devolver la documentación que se le remite una vez realizada la evaluación.

El tiempo establecido para las evaluaciones es de máximo un (1) mes a partir de la confirmación de la recepción de la documentación. Ese plazo podrá ser modificado de mutuo acuerdo entre el editor y el par, siempre cuando no afecte la periodicidad de la revista, la impresión o el tiempo para emitir una respuesta al autor.

\section{Beneficios}

Como retribución a los pares evaluadores, se les hará envío postal de un (1) ejemplar de la edición impresa sin ningún costo y entregada en la dirección consignada en el formato de hoja de vida. También, si es de interés para el par, podrá hacer la solicitud de alguna de las publicaciones editadas y presentes en el catálogo de publicaciones de la UNIVERSIDAD CATÓLICA DE COLOMBIA, previa aprobación de la Editorial y sujeto a la disponibilidad.

Si lo desea tendrá derecho a solicitar una constancia de la colaboración en la evaluación de artículos, la cual solo contendrá el periodo en el cual se realizó la evaluación. También tendrá la posibilidad de aceptar o no la publicación de su nombre, nacionalidad y nivel máximo de formación en la página web de la Revista de Arquitectura en su calidad de colaborador.
El Comité Editorial de la Revista de Arquitectura es la instancia que decide la aceptación de los artículos postulados, el editor selecciona y clasifica solo los artículos que cumplan con los requisitos establecidos en las instrucciones para los autores. Todos los artículos se someterán a un primer dictamen del Comité Editorial, el editor y de los editores de sección, teniendo en cuenta:

- Afinidad temática, relevancia del tema y correspondencia con las secciones definidas.

- Respaldo investigativo.

En caso de que los artículos requieran ajustes preliminares, este será devuelto al autor antes de ser remitidos a pares. En este caso el autor tendrá 15 días para remitir nuevamente el texto con los ajustes solicitados.

Después de la preselección se asignan mínimo dos pares evaluadores internos o externos especializados quienes emitirán su concepto utilizando el formato RevArq FP10 Evaluación de artículos calidad, se garantiza la confidencialidad y el anonimato de autores y árbitros (modalidad doble ciego).

Del proceso de arbitraje se emite uno de los siguientes conceptos que son reportados al autor:

- (AA) Aceptar el artículo sin observaciones.

- (AM) Aceptar el artículo con modificaciones: se podrá sugerir la forma más adecuada para una nueva presentación y se adjuntará la síntesis de los conceptos emitidos por los pares, el autor puede o no aceptar las observaciones según sus argumentos. Si las acepta, cuenta con quince (15) días para realizar los ajustes pertinentes.

- (RA) Rechazar el artículo: en este caso se entregará al autor un comunicado exponiendo las razones por las cuales se rechaza. El autor puede volver a postular el artículo e iniciar nuevamente el proceso de arbitraje, siempre y cuando se evidencien los ajustes correspondientes.

En el caso de presentarse diferencias sustanciales y contradictorias en los conceptos de evaluación, el editor remitirá el artículo a un evaluador más, o un miembro del Comité Editorial podrá asumir la tarea de actuar como el tercer árbitro, esto con el fin de tomar una decisión sobre la publicación del artículo.

El editor y el Comité Editorial se reservan el derecho de aceptar o no la publicación del material recibido. También se reserva el derecho de sugerir modificaciones de forma, ajustar las palabras clave o el resumen y de someterlo a corrección de estilo.

Cuando un artículo es aceptado para su publicación, los derechos de reproducción y divulgación son de la UNIVERSIDAD CATÓLICA DE COLOMBIA, lo cual se formaliza mediante la firma de la autorización de reproducción RevArq FP03 Autorización reproducción artículo, esta autorización de uso no es exclusiva.

\section{NOTAS ACLARATORIAS}

Aunque la recepción del material se notificará por correo electrónico en un plazo máximo de (8) ocho días, los procesos de evaluación, arbitraje, edición y publicación pueden tener un plazo máximo de (12) doce meses. Una vez aprobado y designado el volumen en que será incluido, este se puede tardar alrededor de tres (3) meses. El seguimiento al proceso editorial se podrá hacer por la plataforma digital de la publicación o a petición del autor, el editor informará sobre el estado actual del artículo.

El editor de la Revista de Arquitectura es el encargado de establecer contacto entre los autores, árbitros, evaluadores y correctores, ya que estos procesos se realizan de manera anónima.

La Revista de Arquitectura publica un número limitado de artículos por volumen y busca el equilibrio entre las secciones, motivo por el cual aunque un artículo sea aceptado o continúe en proceso de evaluación, este podrá quedar aplazado para ser publicado en una próxima edición; en este caso, el autor estará en la posibilidad de retirar la postulación del artículo o de incluirlo en el banco de artículos del próximo volumen.
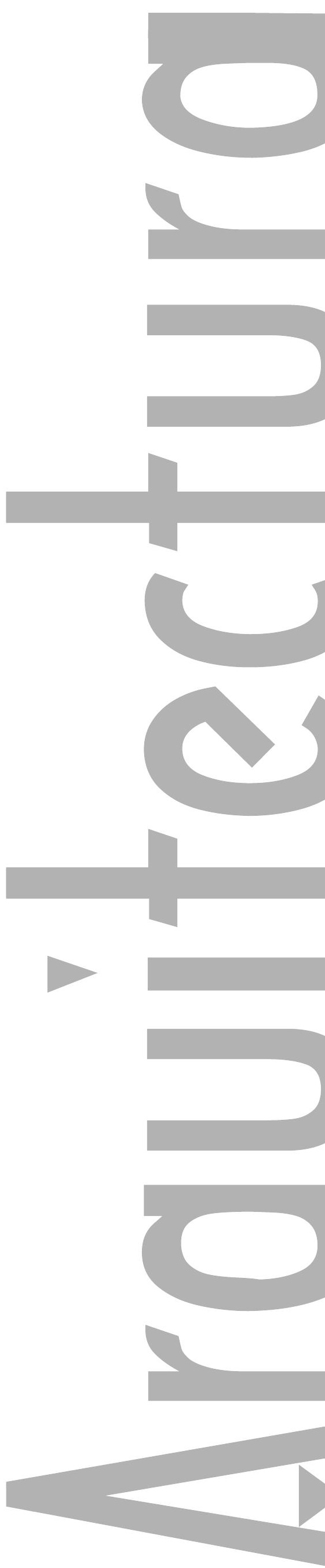
SALAS DE CINE EN PUBLICACIONES DE ARQUITECTURA DE LOS AÑOS TREINTA. UNA MIRADA AL CASO DE LOS CINÉAC

"El DORADO", FRENCH OR GERMAN? A COMPARATIVE STUdY OF MOVIE THEATERS IN STRASBOURG

$$
\text { SHAHRAM HOSSEINABADI }
$$

LES SALLES DE CINÉMA DANS LES PÉRRODIQUES D'ARCHITECTURE DES ANNÉES 1930. UN REGARD AUX CINÉAC

a

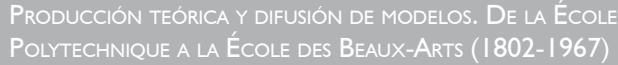
PRODUCTION AND DISSEMINATION OF THEORETICAL MODELS FROM ÉCOLE PolyteCHNIQUe TO THE ÉCOLE DES BeAuX-ARTs (I802-1967) AMANDINE DienER



ARquitectos latinoamericanos en la École des BeauXArts de París en el siglo XIX

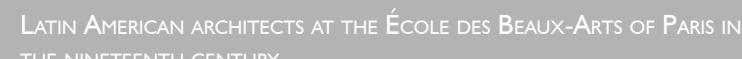

ARCHITECTES LATINO-AMÉRICAINS AU SEIN DE L'ÉCOLE DES BEAUX-ARTS DE PARIS AU XIXÈME SIĖCLE

Luis Manuel Jiménez-MAdera

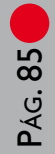

EVANGELIZACIÓN Y PRECARIEDAD. LA ARQUITECTURA RELIGIOSA SIN CORPORACIONES NI ACADEMIAS EN LA NUEVA GRANADA

EVANGELIZATION AND PRECARIOUSNESS. RELIGIOUS ARCHITECTURE

EVANGÉLISATION ET PRÉCARTTÉ. L'ARCHITECTURE RELIIIEUSE SANS GUILDES NI ACADÉMIES DANS LA NOUVELLE-GRENADE

\section{LuCiA ArANGo-LÍÉVANO}

POUR UNE HISTOIRE DE LA TRANSFORMATION DES ÉDIFICES

COMPOSER AVEC LA PRÉEXISTENCE

这

PARA UNA HISTORIA DE LA TH
CON LA PREEXISTENCIA

FOR A HISTORY
THE EXISTING

LAURE JACQUIN

UNA MIRADA A LAS PUBLICACIONES EN LENGUA FRANCESA

Biblografía SELECTA: 2000-20I5 